\title{
Contribution of Carbon Dot Nanoparticles in Electrocatalysis: Development in Energy Conversion Process
}

\author{
Jayasmita Jana*, Yen-Linh Thi Ngo, Jin Suk Chung, and Seung Hyun Hur* \\ School of Chemical Engineering, University of Ulsan, Daehak-ro 93, Nam-gu, Ulsan 44610, Republic of Korea
}

\begin{abstract}
Modern electrochemical energy devices involve generation and reduction of fuel gases through electrochemical reactions of water splitting, alcohol oxidation, oxygen reduction, etc. Initially, these processes were executed in the presence of noble metal-based catalyst that showed low overpotential and high current density. However, its high cost, unavailability, corrosion and related toxicity limited its application. The search for alternative with high stability, durability, and efficiency led scientists towards carbon nanoparticles supported catalysts which has high surface area, good electrical conductivity, tunable morphology, low cost, ease of synthesis and stability. Carbon nanoparticles are classified into two groups based on morphology, one and zero dimensional particles. Carbon nanoparticles at zero dimension, denoted as carbon dots, are less used carbon support compared to other forms. However, recently carbon dots with improved electronic properties have become popular as catalyst as well as catalyst support. This review focused on the recent advances in electrocatalytic activities of carbon dots. The mechanisms of common electrocatalytic reactions and the role of the catalysts are also discussed. The review also proposed future developments and other research directions to overcome current limitations.
\end{abstract}

Keywords : Carbon Dots, Electrocatalysis, Hydrogen Evolution Reaction, Oxygen Evolution Reaction, Oxygen Reduction Reaction

Received: 10 April 2020, Accepted : 23 April 2020

\section{Introduction}

The rapid increase in worldwide energy consumption has led to detrimental impact on the eco-system and economy, and therefore the need for exploration of renewable energy sources. The alternative energy storage and conversion technologies are based on supercapacitors, lithium/sodium ion batteries, metal-air batteries, fuel cells and electrocatalytic water splitting [1]. Electrochemical conversion plays a significant role in energy conversion for production of sustainable fuels and chemicals [2]. Electrochemical devices for the energy conversion and storage are dependent on the constituent material, hence, discovery and modification of suitable materials have been prime concern for the scientists. Rapid advance in nanotechnology provided better options as nanoparticles have high surface to volume ratio and tunable morphology that

*E-mail address: shhur@ulsan.ac.kr, jayasmita.2909@gmail.com DOI: https://doi.org/10.33961/jecst.2020.00934

This is an open-access article distributed under the terms of the Creative Commons Attribution Non-Commercial License (http://creativecommons.org/licenses/by-nc/4.0)
which permits unrestricted non-commercial use, distribution, and reproduction in any which permits unrestricted non-commercial use, distri
medium, provided the original work is properly cited. apparently improves the efficiency for electrochemical processes. Metal nanoparticles have been widely used for electrocatalysis; however, they are expensive and not readily available. The high electron transfer capability, nontoxicity, low cost, simple synthetic route made the carbon nanoparticles an efficient alternative material. Carbon nanoparticles and carbon supported metal nanoparticles have been experimented widely to accomplish a sustainable catalyst. As the electrocatalysts are material dependent, the morphology and dimensionality of the materials are also important. Carbon nanoparticles act significantly at two (2-D), one (1-D) and zero (0-D) dimensional morphologies. However, the high electropotential of the 0-D particles (carbon dots) have grown intense interest for the scientists.

Carbon dots (CD) are fascinating class of recently discovered nanocarbons that comprise discrete, quasi-spherical nanoparticles within the dimension of $10 \mathrm{~nm}$ [3]. CD particles were first discovered in 2004 by $\mathrm{Xu}$ et al. [4] during electrophoretic analysis and purification of single walled carbon nanotubes. Later in 2006, Sun et al. [5] showed that surface passiva- 
tion introduced an intriguing fluorescence of the CD particles. Since their discovery, the research on CD particles have flourished through modification of their optoelectronic properties. CD particles possess tunable emission and wide excitation spectra that have facilitated their use in wide range fluorescence imaging [6]. Such intriguing fluorescence of CD particles originate from quantum confinement, radiative recombination, surface passivation, surface defects, and doping of hetero atoms $[7,8]$. The CD particles are often preferred over traditional organic dyes, metal cluster, fluorescent metal nanoparticles and metallic quantum dots due to their high quantum yield, unique optoelectronic property, photo-resistivity, water solubility, and low toxicity [8]. The adverse chemical and optical properties of CD come from the surface functional groups and the surface defects. For example, CD particles with hydroxyl and carboxylic acid functional groups show excellent solubility properties, although, they have low electron transfer ability due to dislocation of electron density around unsaturated core.

The radiative recombination and electron hole localization is modified in the presence of doped hetero atoms. The interaction within carbon core and surface functional groups facilitate the electron flow within the carbon skeleton. The surface defects and edges provide high surface area. All these factors highly influence optical properties of CD particles. The property and morphology of CQDs highly depend on their synthetic route [3,8]. CD particles have already demonstrated their viability various applications such as sensing, imaging, photovoltaics, environmental remediations, catalysis, electrochemical analysis, etc. as they suppress the limitations of traditional fluorescent probes [3]. Specifically, in the case of electrochemical systems, with their facile charge transfer ability, high surface area, electronic conductivity and chemical inertness, CD particles have prospered as an efficient catalyst.

In this review, we briefly discuss the role of different 0 -D CD particles towards common electrocatalytic reactions.

\section{Electrocatalysis for energy conversion}

The electrochemical reactions governing the energy conversion process are hydrogen evolution reaction (HER), oxygen evolution reaction (OER) and oxygen reduction reaction (ORR) [9]. Water splitting has been employed for hydrogen generation for main component of contemporary clean-energy technologies since its discovery by William Nicolson and Anthony Carlise in 1800 [10]. However, the concept of water splitting was established by Faraday in 1833. Later, Zénobe Gramme and Dmitry Lachinov prescribed low-cost and industrial basis hydrogen synthesis from water splitting, where the generated hydrogen could be used to operate fuel cells. Hydrogen has proven to be an ideal energy carrier, for sustainable energy, due to high energy density and eco-friendly production possibilities [10]. Being a simple proton-electron transfer process without any side reaction, HER is the most studied electrocatalytic reaction [11]. HER measurements are done by a three-electrode system viz. working, reference and counter electrode. The potential at reference electrode is measured with respect to the reference electrode. The HER goes preferably in acidic medium through the following mechanism, [10]

$$
\begin{aligned}
& \mathrm{H}^{+}+\mathrm{e}^{-} \rightarrow \mathrm{H}^{*} \text { (Volmer step) } \\
& \mathrm{H}^{+}+\mathrm{e}^{-}+\mathrm{H}^{*} \rightarrow \mathrm{H}_{2} \text { (Heyrovsky step) } \\
& \mathrm{H}^{*}+\mathrm{H}^{*} \rightarrow \mathrm{H}_{2} \text { (Tafel step) }
\end{aligned}
$$

In alkaline medium the HER might follow the following path [12],

$$
\begin{aligned}
& \mathrm{H}_{2} \mathrm{O}+\mathrm{e}^{-} \rightarrow \mathrm{H}^{*}+\mathrm{OH}^{-} \text {(Volmer step) } \\
& \mathrm{H}^{*}+\mathrm{H}^{*} \rightarrow \mathrm{H}_{2} \text { (Tafel step) }
\end{aligned}
$$

These steps rely on the inherent chemical and electronic properties of the electrode surface. In the first step (1) the catalyst-H bond should be strong enough to cleave the water molecule whereas the next step demands easy catalyst- $\mathrm{H}$ bond breakage for $\mathrm{H}_{2}$ evolution.

For the Volmer step, paired d-electrons are needed to facilitate electron transfer to water molecule while the next steps would prefer partially filled d-electron to facilitate adsorption of $\mathrm{H}^{*}$ moiety [13].The experimental data about Tafel slope helps to assume the mechanism of the reaction. The HER process needs appropriate catalyst that would lower the activation energy and the overpotential. Platinum (Pt), particularly 111 facets of Pt [11]), is a widely used catalyst for HER due to their long-term durability and nearzero over potential [14]. However, the high price and 
low abundance compelled scientists to find alternative catalysts for HER [15]. Also, the poisoning of $\mathrm{Pt}$ catalyst surface by hydroxyl ion limits its application in alkaline medium [16], hence the need for replacement of Pt catalyst with high stability and causing low overpotential. Carbonaceous nanoparticle at zero dimension could act as efficient electrocatalysis along with metal and nonmetal counterpart. The counter reaction for HER during water splitting is OER. HER occurs at cathode while OER occurs at anode. Even though the theoretical voltage for HER and OER at $298 \mathrm{~K}$ are $0 \mathrm{~V}$ and $1.23 \mathrm{~V}$, respectively, practically, extra electricity is needed to overcome the activation energy barrier [10]. In acidic and alkaline medium, the OER follows the following steps respectively, [12],

Acidic medium mechanism for OER:

$$
\begin{aligned}
& \mathrm{H}_{2} \mathrm{O} \leftrightarrow \mathrm{HO}^{*}+\mathrm{H}^{+}+\mathrm{e}^{-} \\
& \mathrm{HO}^{*} \leftrightarrow \mathrm{O}^{*}+\mathrm{H}^{+}+\mathrm{e}^{-} \\
& \mathrm{O}^{*}+\mathrm{H}_{2} \mathrm{O} \leftrightarrow \mathrm{HOO}^{*}+\mathrm{H}^{+}+\mathrm{e}^{-} \\
& \mathrm{HOO}^{*} \leftrightarrow \mathrm{O}_{2}+\mathrm{H}^{+}+\mathrm{e}^{-}
\end{aligned}
$$

Alkaline medium mechanism for OER:

$$
\begin{aligned}
& \mathrm{HO}^{-} \leftrightarrow \mathrm{HO}^{*}+\mathrm{e}^{-} \\
& \mathrm{OH}^{-}+\mathrm{HO}^{*} \leftrightarrow \mathrm{O}^{*}+\mathrm{H}_{2} \mathrm{O}+\mathrm{e}^{-} \\
& \mathrm{O}^{*}+\mathrm{OH}^{-} \leftrightarrow \mathrm{HOO}^{*}+\mathrm{e}^{-} \\
& \mathrm{HOO}^{*}+\mathrm{OH}^{-} \leftrightarrow \mathrm{O}_{2}+\mathrm{H}_{2} \mathrm{O}+\mathrm{e}^{-}
\end{aligned}
$$

OER is a more sluggish process than HER due to the four-electron transfer process. Theoretical thermochemical studies of OER showed that binding energy of surface oxygen played a controlling role [17]. Iridium ( $\mathrm{Ir})$ and ruthenium $(\mathrm{Ru})$ catalysts satisfied the condition and provided their low overpotential and Tafel slope [18], but the scarcity and high price limited their application. In this scenario, the 0D carbon nanoparticle-based catalysts have emerged as their replacement.

ORR is an important cathodic phenomenon that happens in energy-conversion devices like fuel cells and zinc/air battery etc. [19]. Fuel cells were invented by William Grove and Christian Friedrich Schönbein in early 1800s [1]. Fuel cells, operated by taking hydrogen or methanol as fuels and oxygen as redun-

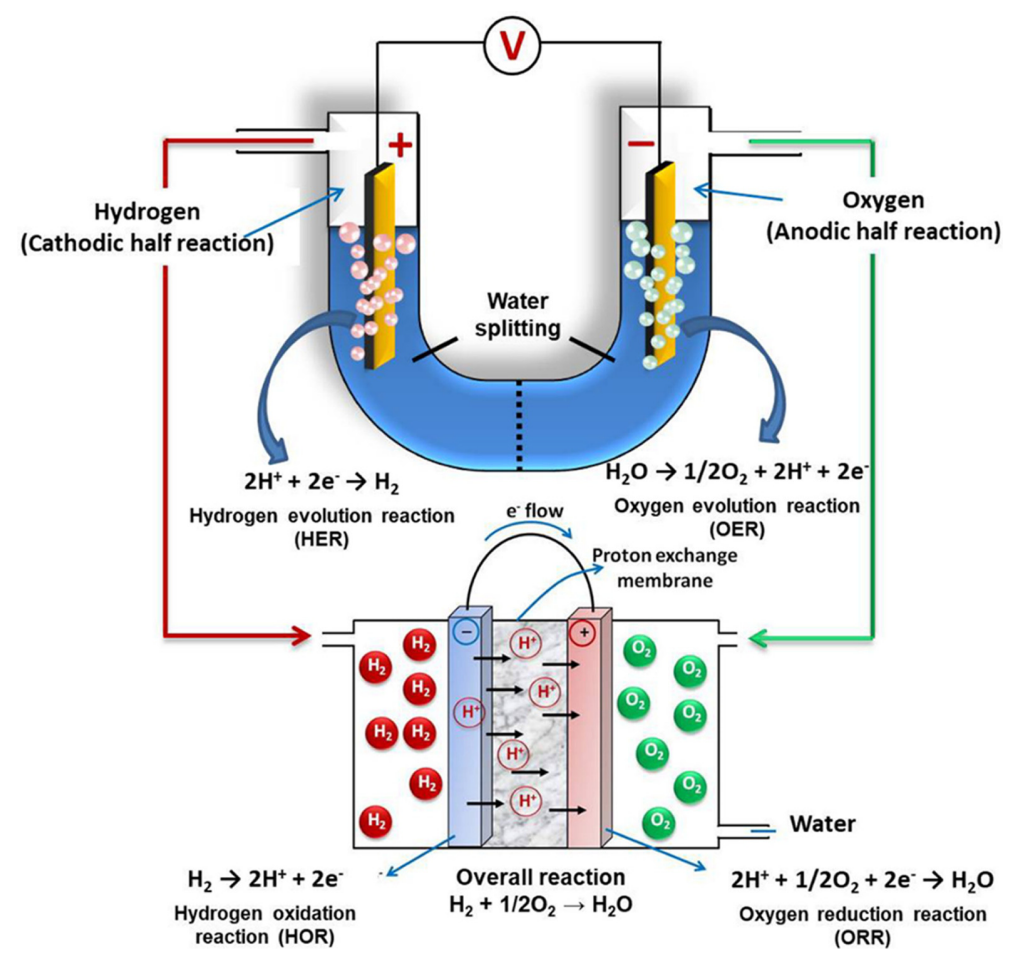

Fig. 1. Schematic representation of energy related applications, i.e., oxygen reduction reaction (ORR) in fuel cell, oxygen evolution reaction (OER), and hydrogen evolution reaction (HER) by water hydrolysis. Reprinted with permission from Reference [9]. Copyright $\odot$ 2017, American Chemical Society. 
dant at room temperature, are solutions to electric vehicles and portable devices [1].

ORR follows four and two electron transfer mechanisms in both acidic and alkaline medium [12],

Acidic medium mechanism for ORR:

$\mathrm{O}_{2}+4 \mathrm{H}^{+}+4 \mathrm{e}^{-} \rightarrow 2 \mathrm{H}_{2} \mathrm{O}$ (Four-electron step)

$\mathrm{O}_{2}+2 \mathrm{H}^{+}+2 \mathrm{e}^{-} \rightarrow \mathrm{H}_{2} \mathrm{O}_{2}$ (Two-electron step)

$\mathrm{H}_{2} \mathrm{O}_{2}+2 \mathrm{H}^{+}+2 \mathrm{e}^{-} \rightarrow 2 \mathrm{H}_{2} \mathrm{O}$

Alkaline medium mechanism for ORR:

$\mathrm{O}_{2}+2 \mathrm{H}_{2} \mathrm{O}+4 \mathrm{e}^{-} \rightarrow 4 \mathrm{OH}^{-}$(Four-electron step)

$\mathrm{O}_{2}+\mathrm{H}_{2} \mathrm{O}+2 \mathrm{e}^{-} \rightarrow \mathrm{HO}_{2}^{-}+\mathrm{OH}^{-}$(Two-electron step)

$\mathrm{H}_{2} \mathrm{O}+\mathrm{HO}_{2}^{-}+2 \mathrm{e}^{-} \rightarrow 3 \mathrm{OH}^{-}$

ORR is also a sluggish reaction as more than one electron is involved. Pt-based electrocatalysts are widely used for ORR. But the unavailability and high price of Pt compelled scientists to find replacements. The electrode structures for these reactions are shown in Fig. 1.

Apart from the HER, OER and ORR, reduction of $\mathrm{CO}_{2}$, alcohol is also used for fuel cells.

The electrolytes used in the reaction have proved to have specific role in terms of stability of catalyst and electrical conductance, e.g. for HER, the electric conductance is higher in acidic than in alkaline and then phosphate buffer medium. The choice of electrolyte influences the reactivity [10]. In modern days the energy related problems can be solved by replacing the conventional energy sources by artificial energyconversion devices. The efficiency of the catalysts in these reactions is examined by monitoring the reaction overpotentials, onset potential, Tafel plots, Koutecky-Levich (K-L) plots. Parameters such as low overpotential and Tafel slope values indicate effective catalysis. The catalytic activity of the CD particles is described using these values.

\section{0-D CD nanoparticles for electrocatalysis}

The electropotential of carbon nanoparticles varies with dimensionality. The kinetics of electron transfer increases from 0-D dot particles to 2-D sheet particles [20]. In this context the dot particles with length to width ration of 1 have become the center of attention. CD particles are classified as carbon nano dot (CND), graphene quantum dot (GQDs), and polymer dots (PDs), which are all 0-D, however, differ in chemical structure and certain electronic properties [21]. CND particles are spherical in shape and consist $\mathrm{sp}^{2} / \mathrm{sp}^{3}$ hybridized carbon core and high oxygen content. CND particles have amorphous nature with no crystal plane, but when crystallinity is present with a lattice parameter of $\sim 0.24 \mathrm{~nm}$, the particles are termed as carbon quantum dots (CQDs) [22]. The photoluminescent origin of CND and CQD particles vary. CND and CQDs are generally synthesized from bio-molecules through top down and bottom up process such as hydrothermal, microwave, laser ablation, chemical reduction, reflux, etc. [8]. CQD particles are commonly synthesized from biomolecules, biomass and organic compounds. Graphene is an allotrope of carbon consisting of honeycomb lattice of carbon atoms with $\mathrm{sp}^{2}$ hybridization [23]. The limitation of zero band gap semiconducting property of graphene can be tuned by change in its electronic property through doping, substrate interaction, change in dimension and morphology [24]. GQD particles overcame the limitations of graphene sheets and are proved to be efficient material for photovoltaics, bio-applications, imaging, devices etc. Figure 2 shows the classification of CD particles [22].

The designing of CD based electrocatalysts needs modification of CD structure [25]. The process includes,

(a) Doping of hetero atoms: Doping of electronegative and electropositive hetero atoms such as, nitrogen $(\mathrm{N})$ and boron $(\mathrm{B})$, breaks the electroneutrality in carbon core by creating electron excess or deficiency and induces facile electronic interaction.

(b) Surface passivation: CD particles contain different surface functional groups that help in facile electron transfer and adhesion of substrate. The electrons donating and accepting functional groups have great role in tuning the property of CD particles.

Such modifications in carbon skeleton of CD particles initiates charge transfer within the carbon skeleton and distort the electronic environment. The energy gap within HOMO and LUMO is modified along with radiative recombination process. The electrocatalytic activity of CD particles are modified through change in the electronic properties based on exposure and generation of active sites. These properties also help CD particles to act as efficient support material towards metal and carbon (graphene, graphitic carbon nitrides etc.) by boosting their surface area to volume ratio and electronic properties [26- 


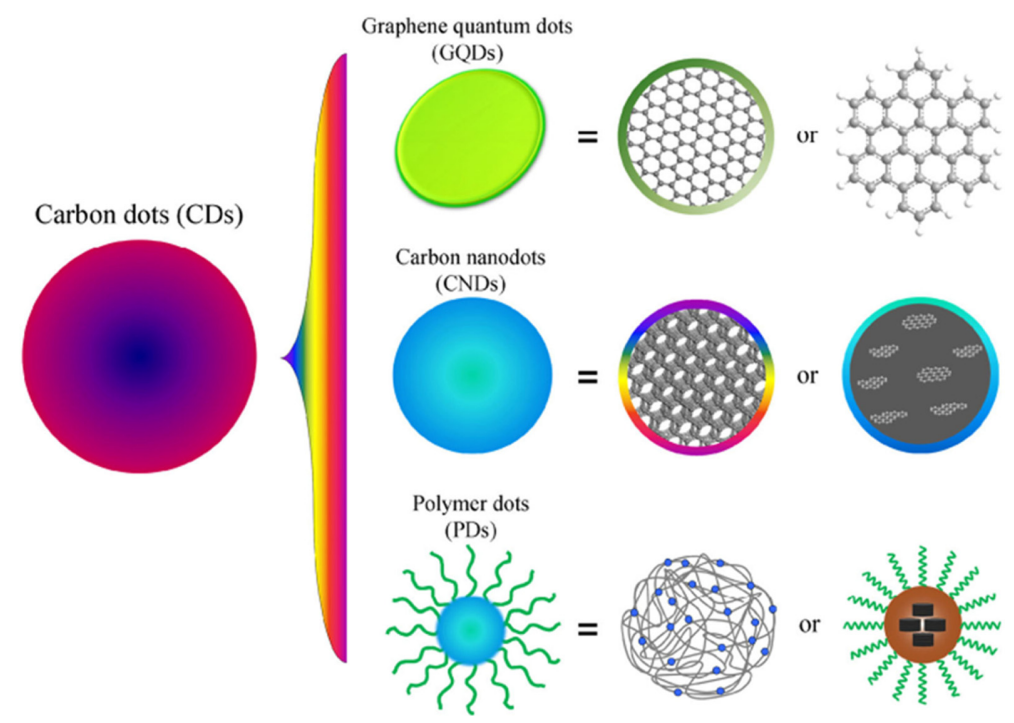

Fig. 2. Three types of CDs and their structures graphene quantum dots (GQDs), carbon nanodots (CNDs), and polymer dots (PDs). Reprinted with permission from Reference [22]. Copyright (C) 2019 American Chemical Society.

31]. Since their first application as electrocatalysts, there has been rapid development in CD based electrocatalysis, specifically, metal free carbon-based catalysts. In the following sections the examples of CD and CD supported catalysts towards electrocatalysis have been discussed.

\subsection{CND/CQD nanoparticles}

The CND/CQD particles with $\mathrm{sp}^{2} / \mathrm{sp}^{3}$ hybridized carbon core act as efficient catalysts. Most CND/ CQD electrocatalysts are hetero atom doped and their activities are often better than commercial metallic catalysts. The electronic behavior of N-doped CNDs (termed as SP2) was utilized by Gao et al. for oxygen reduction catalysis (ORR) through a four electron path in $0.1 \mathrm{M} \mathrm{KOH}$ medium [32]. The SP2 particles, the conglomeration of nanodots, showed a conductivity of $0.466 \mathrm{~S} \mathrm{~cm}^{-1}$. A characteristic ORR peak appeared at ca. $\sim 0.22 \mathrm{~V}$ in the $\mathrm{O}_{2}$ saturated solution, while a featureless character was observed in the $\mathrm{O}_{2}$ absent medium indicating initialization of ORR by SP2 (Fig. 3).

Lie et al. [28] synthesized uniformly N-doped CQDs where they used solvent (N-methyl-2-pyrrolidone and dimethyl-imidazolidinone, with cyclic structures and rich amino groups) as carbon source. They examined its catalytic activity towards ORR in $\mathrm{O}_{2}$-saturated $0.1 \mathrm{M} \mathrm{KOH}$ with $3 \mathrm{M} \mathrm{CH}_{3} \mathrm{OH}$. The peak potential was $-160 \mathrm{mV}$ which remained almost unaltered after 1000 cycles. The presence of pyridine $\mathrm{N}$-atoms caused efficient activity for ORR. Kakaei et al. used CQD to fabricate a gas diffusion electrode for reduction of oxygen in $0.5 \mathrm{M} \mathrm{KOH} \mathrm{[33].} \mathrm{CQD}$ was pasted on carbon paper as an electrode for ORR in fuel cell. At high current region, the Tafel slope was calculated as $111 \mathrm{mV} /$ decade, indicating the significant activity of the catalyst. The results were attributed to the ability of CQD to enhance the solubility and permeability of oxygen in the reaction layer due to its high porosity. Bhattacharyya et al. [34] synthesized a N-doped CQD from a MgII based anionic MOF, $\left\{\left[\mathrm{Mg}_{3}(\mathrm{ndc})_{2.5}\left(\mathrm{HCO}_{2}\right)_{2}\left(\mathrm{H}_{2} \mathrm{O}\right)\right] \cdot\left[\mathrm{NH}_{2} \mathrm{Me}_{2}\right] \cdot 2 \mathrm{H}_{2} \mathrm{O} \cdot \mathrm{DMF}\right.$, ncd $=1,4$-naphthalenedicarboxylate $\}$, to ensure the high porosity and ease of doping. Traces of metallic Co nanoparticles were deliberately incorporated as a part of post synthetic treatment that helped the activity of as-synthesized CQDs for ORR reaction. It was reflected in the Tafel slope values; at higher and lower current density, the slopes were $141 \mathrm{mV} \mathrm{dec}^{-1}$ and $63 \mathrm{mV} \mathrm{dec}^{-1}$, respectively. Atchudan et al. synthesized N-doped CQDs from unripe peach and applied them for electrocatalytic ORR reaction in alkaline medium [35]. They found a prominent $\mathrm{O}_{2}$ reduction peak at $0.45 \mathrm{~V}$ vs. RHE for the $\mathrm{O}_{2}$ saturated $\mathrm{KOH}$ solution with an onset potential of ORR at $0.94 \mathrm{~V}$. They obtained a two electron pathway of $\mathrm{O}_{2}$ 

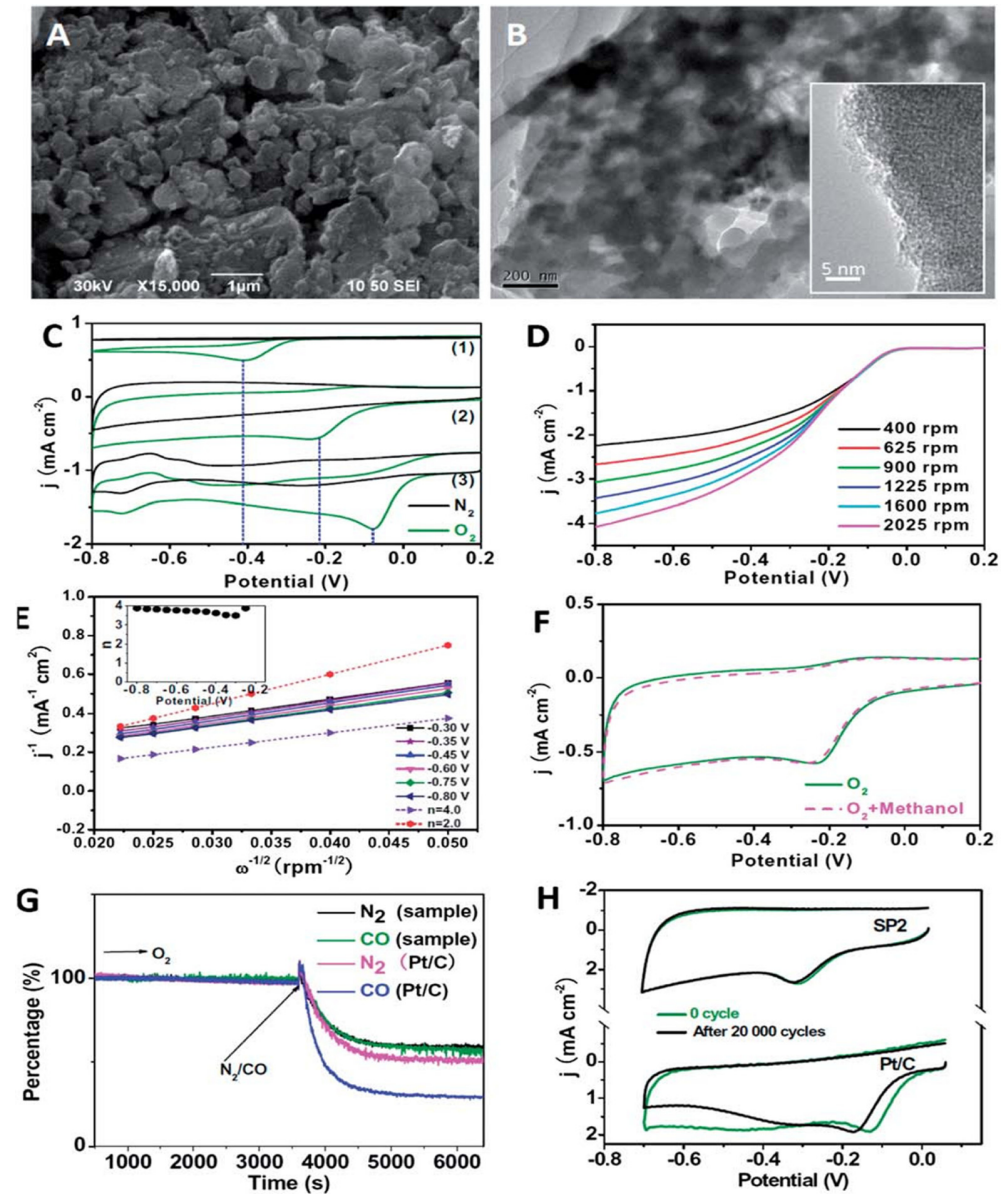

Fig. 3. (A and B) SEM and TEM images of SP2, respectively. (C) CVs of the bare glassy carbon (1), SP2 (2), and Pt/C (3) electrodes in $\mathrm{N}_{2}$ - and $\mathrm{O}_{2}$-saturated $0.1 \mathrm{M} \mathrm{KOH}$ at a scan rate of $10 \mathrm{mV} \mathrm{s} 1$. (D) Linear sweep voltammograms (LSVs) for the ORR on the SP2 electrode in an $\mathrm{O}_{2}$-saturated $0.1 \mathrm{M} \mathrm{KOH}$ solution at a scan rate of $10 \mathrm{mV} \mathrm{s}^{-1}$ and a series of rotation rates from 400 to $2025 \mathrm{rpm}$. (E) The K-L plot $\left(\mathrm{J}^{-1}\right.$ vs. $\left.\omega^{1 / 2}\right)$ at various potentials based on the corresponding LSV data, and the theoretical K-L plots corresponding to $n=2$ and 4 , respectively. The inset plot is the $n$ of the ORR on the SP2 electrode. (F) CV curves of SP2 in $\mathrm{O}_{2}$-saturated $0.1 \mathrm{M} \mathrm{KOH}$ solution with and without $10 \mathrm{vol} \%$ methanol at a scan rate of $10 \mathrm{mV} \mathrm{s}^{-1}$. (G) The percentage of current density (j) vs. time chronoamperometric responses obtained on SP2 and $20 \mathrm{wt} \%$ Pt (JM) electrodes at $0.30 \mathrm{~V}$ in $\mathrm{O}_{2}$-saturated $0.1 \mathrm{M} \mathrm{KOH}$. The arrow indicates the introduction of $\mathrm{N}_{2}$ or $\mathrm{CO}$ into the electrochemical cell. $(\mathrm{H})$ Electrochemical stability of SP2 and $20 \mathrm{wt} \% \mathrm{Pt} / \mathrm{C}$ as determined by continuous $\mathrm{CV}$ scanning in $\mathrm{O}_{2}$-saturated 0.1 M KOH. Scan rate: $50 \mathrm{mV} \mathrm{s}^{-1}$. Reprinted with permission from Reference [32]. Copyright (C) 2014, The Royal Society of Chemistry.

reduction to hydrogen peroxide. Martínez-Periñán et al. [36] reported the effect of surface functional groups on ORR in acidic and alkaline medium. They fabricated amide $\left(\mathrm{CD}-\mathrm{CONH}_{2}\right)$ and carboxylic acid functionalized (CD-COOH) CND particles and examined their electrocatalytic properties towards ORR in acidic and alkaline medium. A suitable onset potential of $-0.28 \mathrm{~V}$ (vs. SCE) was obtained for CD$\mathrm{COOH}$ modified the screen-printing electrode in alkaline medium. Datta et al. [37] showed a metal free water oxidation by CQD with entrapped 5hydroxymethyl-2-furaldehyde (5-HMF) at carbon skeleton. They proposed that the 5-HMF molecules in close vicinity to the catalytically active sites containing $\mathrm{C}=\mathrm{O}$ groups could extract the $\mathrm{OH} / \mathrm{OOH}$ radicals and increase the in situ $\mathrm{H}_{2} \mathrm{O}$ concentration to facilitate the $\mathrm{O}_{2}$ evolution. The electrocatalytic behavior of the CQDs was dependent on 5-HMF con- 
centration. The highest concentration of 5-HMF decently exhibited low $0.21( \pm 0.03) \mathrm{V}$ overpotential and generated current density up to $33.6( \pm 2.3) \mathrm{mA}$ $\mathrm{cm}^{-2}$. Shen et al. [38] prepared a CND from melamine and glutaraldehyde and used them for electrocatalytic ORR in alkaline medium with an onset potential and current density of $-0.169 \mathrm{~V}$ and $2.69 \mathrm{~mA} \mathrm{~cm}^{-2}$, respectively. The CND particles were then coupled with silver nanoparticles to achieve superior catalytic activity with onset potential of $-0.081 \mathrm{~V}$ and a current density of $4.09 \mathrm{~mA} \mathrm{~cm}^{-2}$ at $-0.5 \mathrm{~V}$.

\subsection{CND/CQD supported metallic and nonmetal- lic nanoparticles}

In their study, Shen et al. [38] reported that the composite of the as-synthesized N-doped CND with silver nanoparticle (AgNP) provided better activity towards ORR compared to N-CND. The CND possessed both $\mathrm{p}$ - and n-type conductivities from the Mott-Schottky relationship. The catalytic property of metal was synergistically improved by the high surface area and facile electron transport property of CND particles. There are certain other reports of such synergistic interaction within CND-metal/metal oxide/metal phosphide etc. towards electrocatalysis. Along with that, nonmetal carbonaceous counter parts have also been studied as the alternative for metal. Karim Kakaei reported the enhanced activity of platinum $(\mathrm{Pt})$ nanoparticles combined with CQDs towards ORR [39]. The activity of Pt/CQD composite was compared with $\mathrm{Pt} / \mathrm{C}$ catalyst. The durability was checked by chronoamperometric measurements at $0.5 \mathrm{~V}$ vs $\mathrm{Ag} / \mathrm{AgCl}$ in an $\mathrm{O}_{2}$-saturated $0.1 \mathrm{M} \mathrm{HClO}_{4}$ electrolyte $(89.4 \%$ relative current persisted in acidic medium after 21000 s compared to $81.6 \%$ for $\mathrm{Pt} / \mathrm{C}$ ), which showed that the composite can further be used for fuel cells. Bao et al. [40] prepared CQD/nickelcobalt phosphide (CQDs@NiCoP) catalysts through a facile annealing method for electrocatalytic hydrogen evolution reaction (HER), which yielded a lower initial overpotential than pure for NiCoP (108 vs. $182 \mathrm{mV}$ ) and a lower Tafel slope ( $\left.80 \mathrm{mVdecade}^{-1}\right)$. CQD aided high catalyst conductivity and significantly accelerated charge transfer. Li et al. found CQD loaded ruthenium nanoparticles (Ru@CQDs480) to be efficient electrocatalyst for reduction of hydrogen at alkaline medium [41]. They varied the medium $\mathrm{pH}$ and observed that even at extreme alkaline condition the as-formed Ru@CQDs480 exhibited significant cata- lytic behavior with onset overpotential of $0 \mathrm{mV}$, a Tafel slope of $47 \mathrm{mV} \mathrm{decade}{ }^{-1}$, and good durability (Fig. 4).

Li et al., reported CQD supported enhanced activity of ruthenium $(\mathrm{Ru})$ nanocatalyst for HER [31]. The catalytic activity largely depended on the crystallinity and confinement effects. The experimental results showed that $\mathrm{Ru}$ nanoparticles were successfully anchored by strong coordination interactions between the $\mathrm{d}$ orbitals of $\mathrm{Ru}$ and the surface functional groups of CQDs, which is beneficial to the confinement of $\mathrm{Ru}$ nanoparticles around the CNDs and to prevent their aggregation. The Tafel slope with the catalyst at its optimized condition was $\sim 63 \mathrm{mV} \mathrm{decade}^{-1}$. From the experimental data, they proposed Volmer-Heyrovsky mechanism for HER. A rhodium (Rh)/silicon quantum dot/CQD nanocomposite was reported by Dang et al. for HER [42]. The silicon quantum dots limited the size of $\mathrm{Rh}$ and prevented the aggregation and the CQDs greatly increased the electron transportation during the catalytic process. The catalyst showed a low overpotential of $36 \mathrm{mV}$ at $10 \mathrm{mAcm}^{-2}$, low Tafel slope of $26 \mathrm{mV} \cdot \mathrm{dec}^{-1}$ and long-term stability. Nanocomposites based on transition metal oxide and carbon nanostructure are of low cost and provide high activity and stability. Liu et al., prepared a general route for synthesis of $\mathrm{Ru}-\mathrm{M}(\mathrm{M}=\mathrm{Ni}, \mathrm{Cu}, \mathrm{Mn})$ bimetallic nanoparticle and CND hybrid, and out of three kind of composite, RuNi/CQD exhibited highest performance for HER. [43]. The overpotentials of 13,58 , and $18 \mathrm{mV}$ were shown by $\mathrm{RuNi} / \mathrm{CQDs}$ at a current density of $10 \mathrm{mAcm}^{-2}$ in $1 \mathrm{M} \mathrm{KOH}, 0.5 \mathrm{M}$ $\mathrm{H}_{2} \mathrm{SO}_{4}$, and 1M PBS, respectively, for Ru loading at $5.93 \mu \mathrm{gRucm}^{-2}$. The role of CQD particles was tested by replacing CQD with other carbon materials, but it was observed that CQD based particles showed high activity and durability. This might be due to strong interaction within d-orbital of $\mathrm{Ru}$ and functional groups of CQD which further prevented the aggregation of the particles. Theoretical studies revealed that Ni doping caused a moderate weakening of the hydrogen bonding energy of nearby surface $\mathrm{Ru}$ atoms, that played a critical role in improving the HER activity. Li et al. [44] prepared a CQDs decorated $\mathrm{Ba}_{0.5} \mathrm{Sr}_{0.5} \mathrm{Co}_{0.8} \mathrm{Fe}_{0.2} \mathrm{O}_{3-\delta}$-perovskite nanofibers (CQDs@BSCF-NFs) catalyst for OER. The catalyst achieved a low overpotential $\left(0.35 \mathrm{~V}\right.$ at $\left.10 \mathrm{~mA} \mathrm{~cm}^{-2}\right)$, high current density $\left(140.8 \mathrm{mAcm}^{-2}\right.$ at a potential of $1.65 \mathrm{~V}$ vs. RHE), and high stability. The high catalytic 

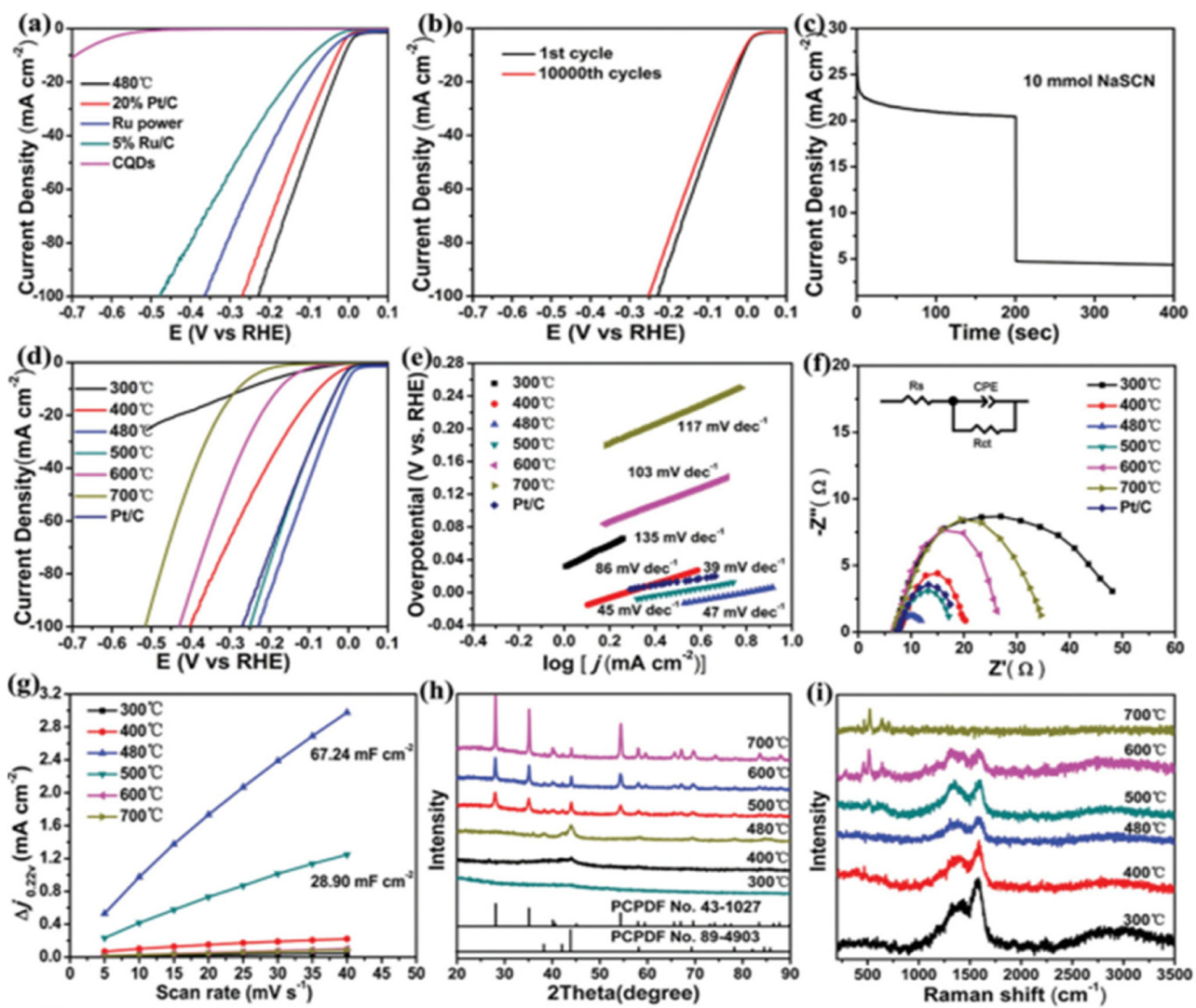

(j)

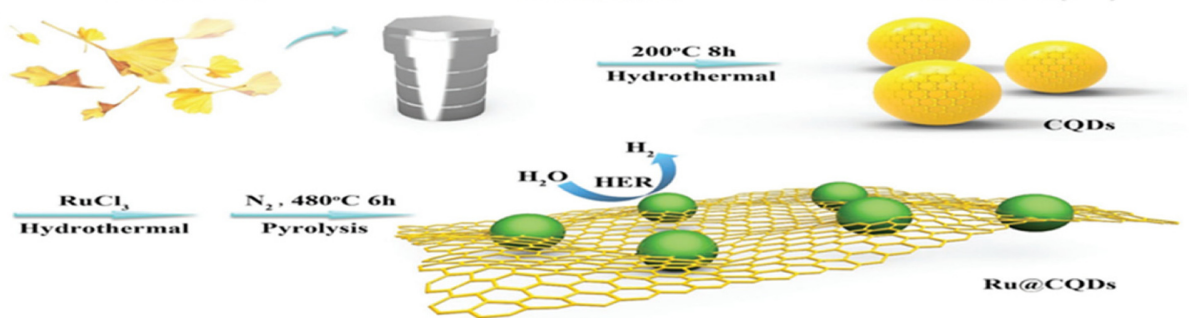

Fig. 4. (a) HER polarization curves for the Ru@CQDs480 and CQDs, Ru powder, 5\% commercial Ru/C and 20\% commercial Pt/C. (b) Durability test for Ru@CQDs480 in $1 \mathrm{~m} \mathrm{KOH}$ before and after 10000 cycles. (c) Current-time curve of the Ru@CQDs480 before and after the addition of $\mathrm{SCN}^{-}$ions in $1 \mathrm{~m} \mathrm{KOH}$. $(\mathrm{d}, \mathrm{e}) \mathrm{HER}$ polarization curves $(\mathrm{d})$ and Tafel plots (e) for the Ru@CQDs annealed at different temperatures and Pt/C catalyst. f) Nyquist curves for the Ru@CQDs annealed at different temperatures and $\mathrm{Pt} / \mathrm{C}$ catalyst at $\eta=10 \mathrm{mV}$. g) Current density as a function of the scan rate for the Ru@CQDs annealed at different temperatures. h) XRD (i) and Raman pattern of Ru@CQDs calcinated at different temperature. (j) Schematic illustration of the synthesis of the Ru@CQDs480 electrocatalyst. Reprinted with permission from Reference [41]. Copyright (C) 2018, WILEY-VCH Verlag GmbH \& Co. KGaA, Weinheim.

activity was attributed to high surface area of hollow nanofibers further increased by CQD and the numerous surface oxygen vacancies as well as the synergy between CQD and BSCF. Tian et al. [45] incorporated CQDs in $\mathrm{MnO}_{2}$ nanoflower, increasing the surface area, electron transfer speed, and electrical conductiv- ity of the catalyst and used for OER in alkaline medium: with an overpotential of $343 \mathrm{mV}$ and a low Tafel slope of $43.6 \mathrm{mV} \mathrm{dec}^{-1}$, it was a good catalysis. Zhang et al. [46] showed enhanced specific surface area and electric conductivity in a N,S-codoped CQD supported $\mathrm{Co}_{9} \mathrm{~S}_{8}$ nanoparticles $\left(\mathrm{Co}_{9} \mathrm{~S}_{8} / \mathrm{CD} @ \mathrm{NSC}\right)$ 
where CQD helped in smooth distribution of $\mathrm{Co}_{9} \mathrm{~S}_{8}$ nanoparticles in the matrix. The obtained $\mathrm{Co}_{9} \mathrm{~S}_{8} /$ CD@NSC exhibited an excellent ORR and OER bifunctional catalytic activity and a great long-term durability, with a half-wave potential of $0.84 \mathrm{~V}$ vs. reversible hydrogen electrode (RHE) for the ORR and a low potential of $1.62 \mathrm{~V}$ versus RHE at $10 \mathrm{~mA}$ $\mathrm{cm}^{-2}$. These results were better than those exhibited by commercial $\mathrm{Pt} / \mathrm{C}$ and $\mathrm{RuO}_{2}$ catalysts. Later, they used the $\mathrm{Co}_{9} \mathrm{~S}_{8} / \mathrm{CD} @$ NSC catalyst for zinc/air battery with low charge/discharge voltage gap of $0.62 \mathrm{~V}$ and great cycling stability of over $125 \mathrm{~h}$ at $10 \mathrm{~mA} \mathrm{~cm}$. Zhao et al prepared $\mathrm{CQD} / \mathrm{SnO}_{2}-\mathrm{Co}_{3} \mathrm{O}_{4}$ composite for highly efficient electrochemical water oxidation [47]. Their experimental results showed that the Co atoms were considered as the active center, the nano sized $\mathrm{SnO}_{2}$ enhanced electronic conductivity and the insoluble CQDs layer on the surface effectively protected the catalyst. CQD also enhanced the electrocatalytic property with surface modification and doped hetero atoms. Tang et al. [48] reported a CQD-NiFe layered double-hydroxide (NiFe-LDH) composite for electrocatalytic water splitting with a high electrocatalytic activity (overpotential of $\sim 235 \mathrm{mV}$ in $1 \mathrm{M} \mathrm{KOH}$ at a current density of $10 \mathrm{~mA} \mathrm{~cm}^{-2}$ ) and stability for oxygen evolution. CQD increased the electroactivity and durability of $\mathrm{NiFe}-\mathrm{LDH}$ through the bonding and interaction between the CQDs and the pure NiFeLDH nanoplate. Canton-Vitoria et al. synthesized a $\mathrm{CQD} / \mathrm{MoS}_{2}$ ensemble and used it for HER [49]. The quenching in $\mathrm{CD}$ fluorescence by $\mathrm{MoS}_{2}$ indicated electronic interaction between the two components. Yang et al. [16] prepared a nickel nanoparticle/CQD hybrid for hydrogen evolution in alkaline medium. The obtained hybrid showed good catalytic ability for HER with an onset potential comparable to that of platinum wire and a low Tafel slope of $98 \mathrm{mV} \mathrm{dec}^{-1}$. The good catalytic activity might be attributed to the synergistic interaction between nickel nanoparticles and CQDs at the Ni-O-C interface. Shih et al. [50] designed $\mathrm{Cu}_{2-\mathrm{x}} \mathrm{S} / \mathrm{CQD}$ nanoparticles that was used as cathode electrode material for ORR in direct methanol fuel cells. The ORR was carried out in acidic medium. The synthesized nanocomposite contained $\mathrm{Cu}_{9} \mathrm{~S}_{5}$ and $\mathrm{Cu}_{2} \mathrm{~S}$. The catalyst provided a limiting density of $-1.77 \mathrm{~mA} \mathrm{~cm}^{-2}$ at a scan rate of $5 \mathrm{mV} \mathrm{s}^{-1}$ and rotation rate of $3600 \mathrm{rpm}$. Wang et al. [51] developed a heteroatom doped CQD-metal sulfide hybrid for HER in acidic medium. They prepared a N,P- doped CQD/CoS $\mathrm{S}_{2}$ hybrid through hydrothermal method, which showed long term stability and low overpotential during the HER. Zhang et al. [52] prepared a CQD/molybdenum phosphide (MoP) nanohybrid for HER in alkaline medium. The CQDs helped to alleviate the agglomeration and surface oxidation of MoP nanoparticles, ensuring that each MoP nanoparticle could be electronically addressed to elevate the electrocatalytic activity of the nanohybrid. The optimized CQDs/MoP hybrid synergistic catalysis toward HER in $1 \mathrm{M} \mathrm{KOH}$ electrolyte with a low onset potential of $-0.08 \mathrm{~V}$ and a small Tafel slope of $56 \mathrm{mV} \mathrm{dec}{ }^{-1}$. The nanohybrid showed high durability with negligible current loss for at least $24 \mathrm{~h}$. Zhao et al. [53] prepared a CQD supported cobalt phosphate (CoPi) nanocomposite for electrocatalytic water splitting. The nanocomposite showed efficient catalysis for OER in both alkaline and neutral medium. The activity was a result of the synergistic interaction within CQD and CoPi. The CQD layer on the CoPi surface averted the CoPi from dissolution of enhancing the stability of the composite electrocatalyst. In neutral condition, the Tafel slope was $59 \mathrm{mV}$ per decade. Cao et al. [54] prepared a N-doped CQD/ graphene (N-CQD/G) composite and increased its activity for ORR by combining it with $\mathrm{Pt}$ nanoparticles $(\mathrm{Pt} / \mathrm{N}-\mathrm{CQD} / \mathrm{G})$. The composite was advanced with highly distributed $\mathrm{Pt}$ nanoparticles with small size, N-doping, and strong interaction between metal and support, as well as the unique structure of $\mathrm{N}$ CQD/G hybrids with abundant edges and doping sites, high surface area, large pore size and high electrical conductivity. The structural advantages reflected in their high activity and durability (the mass activity decreased a $\sim 32 \%$ after 5000 cycles). A three component electrocatalyst composed of $\mathrm{Co}_{3} \mathrm{O}_{4}$-CQD$\mathrm{C}_{3} \mathrm{~N}_{4}$ was designed by Guo et al. [55] for reduction of carbon dioxide to syngas. The composite was able to control the balance between the HER channel and $\mathrm{CO}_{2}$ reduction channel and initiated the reaction of $\mathrm{CO}_{2}$ reduction to $\mathrm{CO}$ in aqueous solutions at a low overpotential $(0.17 \mathrm{~V})$ while the total current density reached up to $15 \mathrm{~mA} / \mathrm{cm}^{2}$ at a potential of $-1.0 \mathrm{~V}$. A sandwich-like electrode with tungsten nitride nanosheets decorated with CQD (N-CDs@WN hybrid) was designed by Zhang et al. [56] for oxygen reduction. The hierarchical structure with large specific area, numerous active sites, and synergistic effect between CQD and WN might facilitate the 
conductivity and mass transfer during the ORR process. The low Tafel slope of $79 \mathrm{mV} \mathrm{dec}^{-1}$ indicated high catalytic efficiency. Even after 20000s, the catalyst retained $\sim 82.3 \%$ of its original ORR performance.

Nevertheless, metal free CQD/carbon nanoparticle composites also showed efficient electrocatalytic activity. Hu et al. reported a N-doped CQD decorated graphene composite for ORR [57]. The graphene was support and CQD provided the active sites. The cata- lyst showed comparable catalytic activity, durability, stability and selectivity with commercial platinum electrocatalyst during alkaline ORR. Zhang et al. [27] examined the superior behavior of CQD/reduced graphene oxide (rGO) composite compared to CQD doped rGO. They prepared a N,S-dual doped CQD/ rGO nanocomposite and analyzed its catalytic activity towards ORR in $\mathrm{N}_{2}$-saturated and $\mathrm{O}_{2}$-saturated $0.1 \mathrm{M}$ $\mathrm{KOH}$. The doping of hetero atom played an important role in catalysis. The low Tafel slope $\left(71 \mathrm{mVdecade}^{-1}\right)$
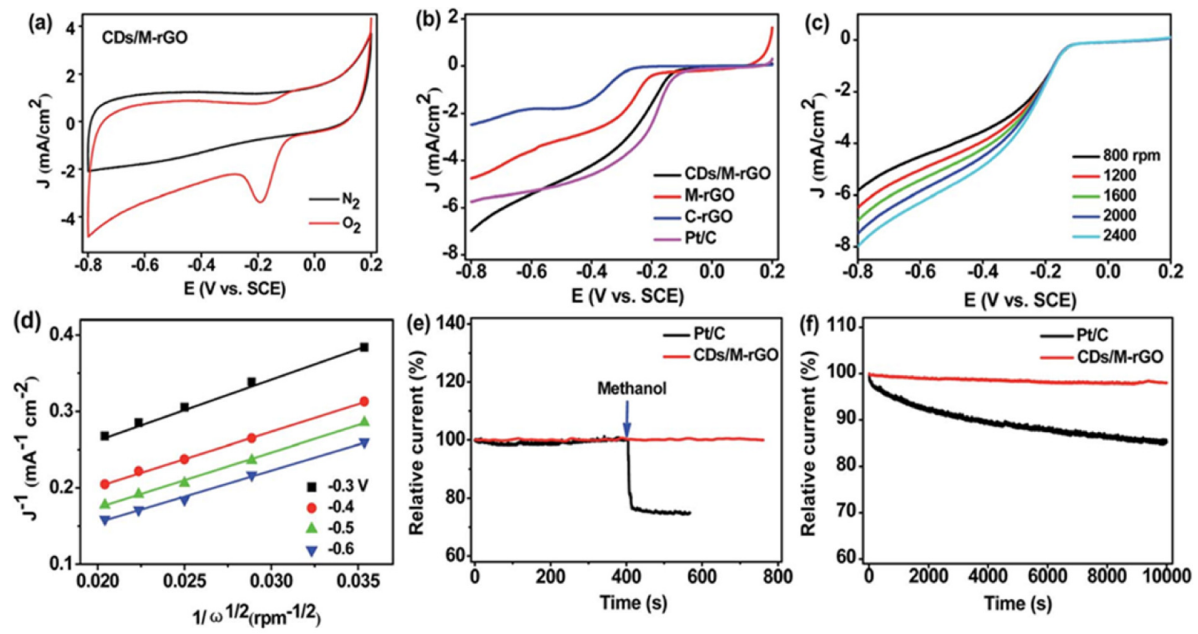

(g)
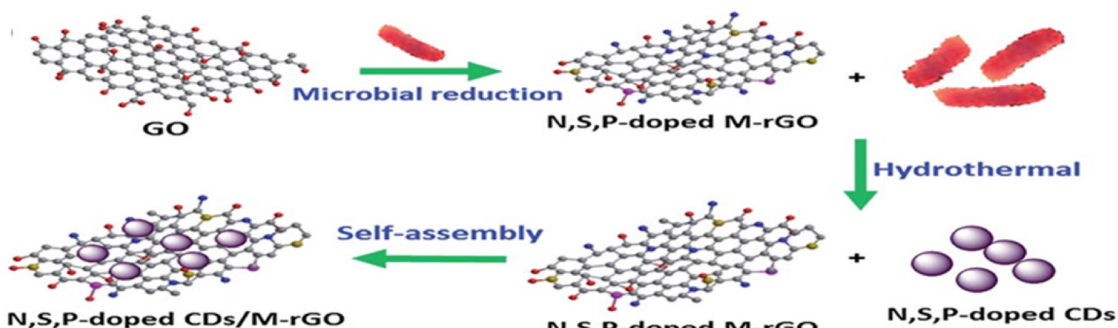

(h)

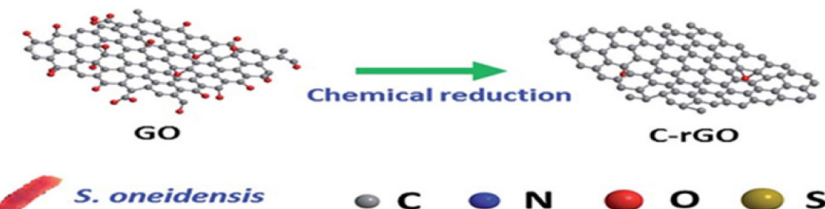

Fig. 5. (a) CV curves of the $\mathrm{CDs} / \mathrm{M}$-rGO in $\mathrm{N}_{2}$-saturated and $\mathrm{O}_{2}$-saturated $0.1 \mathrm{M} \mathrm{KOH}$ solutions at a scan rate of $10 \mathrm{mV} \mathrm{s} 1$; (b) RDE curves of C-rGO, M-rGO, CDs/M-rGO and Pt/C in $\mathrm{O}_{2}$-saturated $0.1 \mathrm{M} \mathrm{KOH}$ solutions at a scan rate of $10 \mathrm{mV}$ s1 and a rotation speed of $1600 \mathrm{rpm}$; (c) RDE curves of the CDs/M-rGO at different rotation rates; (d) K-L plots at different potentials for the CDs/M-rGO; (e) chronoamperometric responses to the injection of methanol into an $\mathrm{O}_{2}$-saturated $0.1 \mathrm{M}$ $\mathrm{KOH}$ solution at the $\mathrm{CDs} / \mathrm{M}-\mathrm{rGO}$ and $\mathrm{Pt} / \mathrm{C}$ electrodes; (f) chronoamperometric responses of the $\mathrm{CDs} / \mathrm{M}-\mathrm{rGO}$ and $\mathrm{Pt} / \mathrm{C}$ electrodes at $0.4 \mathrm{~V}$ (vs. SCE) in $\mathrm{O}_{2}$-saturated $0.1 \mathrm{M} \mathrm{KOH}$ solutions, normalized to the initial current responses. Reactions and operations involved in the process of fabricating CDs/M-rGO (g); the process of fabricating C-rGO (h). Reprinted with permission from Reference [59]. Copyright (C) 2016, The Royal Society of Chemistry. 
indicated high catalytic activity. Wang et al. [58] reported that the effect of defect in the CQD/ graphene composite helped to achieve high catalytic activity towards ORR. The composite was used as an air cathode material for zinc/air battery. Zhou et al. [59] synthesized a CQD decorated reduced graphene oxide using microorganisms. Both CQD and graphene were doped with hetero atoms; N, S, and P. This hybrid had long term stability and significant catalytic activity towards reduction of oxygen through a four electron pathway in alkaline medium. The catalytic property was as a result of the combined effect of heteroatom doping and numerous surface/edge defects that induced the high-density distribution of highly active and stable catalytic sites. Again, the strong coupling effects between CQDs and graphene facilitated the charge transport and ionic motion during the reduction of oxygen. The electrochemical studies and fabrication process of the catalyst are shown in Fig. 5.

Niu et al. [60] prepared a nitrogen rich CQD supported graphene oxide for reduction of oxygen in alkaline medium. The as-prepared hybrid showed positive onset potential $(0.13 \mathrm{~V}$ vs. $\mathrm{Ag} / \mathrm{AgCl})$ and high kinetic current density (up to $18.4 \mathrm{~mA} \mathrm{~cm}^{-2}$ at $0.70 \mathrm{~V}$ ) comparable to commercial $\mathrm{Pt} / \mathrm{C}$ catalyst during ORR. A N-doped CQDs supported carbon nanosheet (N-CNA) particle was used as electrocatalyst for ORR in an $\mathrm{O}_{2}$-saturated $0.1 \mathrm{M} \mathrm{KOH}$ solution by Zhang et al. [61]. The N-CNA showed a small over potential of $-0.08 \mathrm{~V}$ that could be compared to intrinsic low over potential for ORR. The catalytic activity was comparable to commercial $\mathrm{Pt} / \mathrm{C}$. The wide current plateau within a wide potential range indicated high performance of the N-CNA electrocatalyst. Another synergistic interaction within N-doped CQD and graphene was reported by Liu et al. [62], showing that the synergistic interaction within CQD and graphene oxide boosted the catalytic activity and the doping could modify the charge density on the electrocatalyst and weaken the adsorption of reaction intermediates $(\mathrm{O}$ and $\mathrm{OOH})$. The composite was used for ORR process, through a four-electron way mechanism, with an onset potential of $-95 \mathrm{mV}$ and kinetic current density of $12.7 \mathrm{~mA} \mathrm{~cm}^{-2}$ at $-0.7 \mathrm{~V}$ (vs. Ag/ $\mathrm{AgCl})$. The results indicated good catalytic behavior. The catalyst also possessed significant stability ( $\sim 88 \%$ retention of current density even after $40000 \mathrm{~s}$ ), durability and methanol tolerance.

\subsection{GQD nanoparticles}

Colloidal GQDs are new addition to 0-D carbonaceous nanoparticles. GQDs with high electrical conductivity and active sites have been used for electrocatalysis. Li et al. [63] applied solution chemistry approach for the synthesis of N-doped GQDs and explored their size with respect to their catalytic property for ORR in $0.1 \mathrm{M} \mathrm{KOH}$. The doping of hetero atom and size of the catalyst played a major role. The linear sweep voltammetry showed that the Ndoped GQDs have high, size-dependent electrocatalytic activity for the ORR They prepared three kinds of GQDS (1, $2 \mathrm{~N}$-doped and 3-undoped) and demonstrated via both experimental and theoretical data, that the size and abundance of nitrogen atom with specific bonding configuration have an important role in the catalysis. Figure 6 shows the results of electrochemical studies and the structure of GQDs.

Yan et al. prepared GQDs from graphene flakes for ORR [64]. They found that the GQD catalyst showed a high electrocatalytic activity for the ORR, with a 70 times enhancement in voltammetric current in oxygen saturated $\mathrm{KOH}$ compared to that in N-GQD. The ORR onset potential was $-0.25 \mathrm{~V}$ with the reduction peak at $-0.45 \mathrm{~V}$. The ORR followed a two-electron mechanism. Guin et al. [65] used green luminescent GQDs as impending electrocatalyst for reduction of $\mathrm{K}_{3}\left[\mathrm{Fe}(\mathrm{CN})_{6}\right]$. The standard rate constant of this heterogeneous reaction was $2.69 \times 10^{-3} \mathrm{~cm} \mathrm{~s}^{-1}$ within a scan rate of $25-300 \mathrm{mV} \mathrm{s}^{-1}$. They proposed that the edge functionalities and the basal graphitic $\pi$-units facilitated the outer-sphere heterogeneous electron transfer kinetic of the bench-mark redox mediator, which could be further used for various electrochemical applications. Favaro et al. [66] synthesized singly and doubly doped graphene oxide quantum dots with $\mathrm{N}$ and $\mathrm{B}$ hetero atoms for ORR. Through DFT calculation, they determined that the selectivity of the reaction is controlled by the oxidation states of the dopants. The as-prepared GQDs follow a two-electron reduction path that leads to the formation of hydrogen peroxide, whereas after the reduction with $\mathrm{NaBH}_{4}$, the same materials favor a four-electron reduction of oxygen to water.

\subsection{GQD supported metallic and nonmetallic nanoparticles}

The electronic interaction between GQD and metallic nanoparticles results in the modification of 

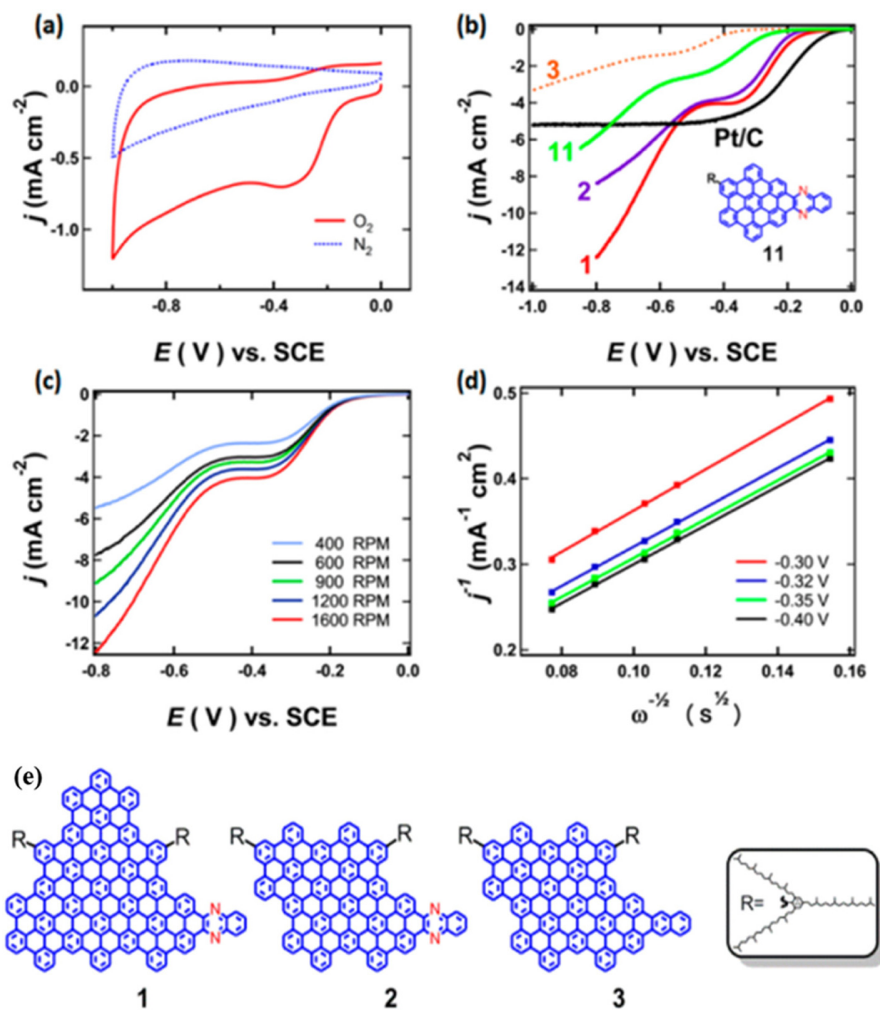

Fig. 6. (a) CV curves (scanning rate of $50 \mathrm{mV} \mathrm{s}^{-1}$ ) of 1 on a glassy carbon $\mathrm{RDE}$ in a $\mathrm{N}_{2}$ - and an $\mathrm{O}_{2}$-saturated $0.1 \mathrm{M} \mathrm{KOH}$ solution. (b) LSV curves $\left(10 \mathrm{mV} \mathrm{s}^{-1}\right)$ for $1-3$ and $\mathrm{Pt} / \mathrm{C}$ on a $\mathrm{RDE}(1600 \mathrm{rpm})$ in an $\mathrm{O}_{2}$-saturated $0.1 \mathrm{M} \mathrm{KOH}$ solution. Also shown is the LSV curve for 11, a much smaller N-substituted heterocycle with structure shown in the inset. (c) LSVs (10 $\mathrm{mV} \mathrm{s}^{-1}$ ) for 1 on a RDE in an O2-saturated $0.1 \mathrm{M} \mathrm{KOH}$ solution with various rotating speeds. (d) Koutecky-Levich plots for 1 obtained from the LSV curves in (c) at various voltage values. A global fitting of the plots reveals that the number of electrons transferred per $\mathrm{O}_{2}$ molecule is 3.9. (e) Structures of N-Doped GQD 1, 2 and an Undoped GQD 3 for Comparison. Reprinted with permission from Reference [63]. Copyright (C) 2012 American Chemical Society

the catalytic properties of the metals and makes GQD an active support. Deming et al. [67] prepared a Pd nanoparticle supported N-doped GQD for the electroreduction of oxygen in alkaline medium. The catalyst worked better than Pd supported on undoped GQDs and $\mathrm{Pt} / \mathrm{C}$. The $\mathrm{Pd}$ atoms had a strong interaction with the pyrrole ring. The p-type pyridinic and pyrrolic N-centers in N-doped GQDs increased the catalytic activity in terms of manipulating the Pdoxygen intermediate. The highest specific current density of $25.4 \mathrm{~A} / \mathrm{m}^{2}$ and best Tafel slope of $120 \mathrm{mV} /$ dec were obtained for the nitrogen centers felicitated charge transfer and provided optimal binding condition within metal surface and oxygenated intermediates. Deming et al. also reported about Pd supported GQD nanocatalyst [68]. Voltammetric studies showed apparent electrocatalytic activity toward oxygen reduction in alkaline medium. The peak activity of the sample was attributed to the optimal interactions between Pd and GQD, where the GQD defects promoted charge transfer from metal to GQDs and weakened interactions with oxygenated intermediates, leading to enhanced ORR activity. The corresponding defect concentration was higher than that identified with the platinum counterparts due to the stronger affinity of oxygen to palladium. The best Tafel slope was $71.6 \mathrm{mV} / \mathrm{dec}$ and the highest kinetic current density of $1.08 \mathrm{~A} / \mathrm{m}^{2}$ at $+0.90 \mathrm{~V}$ for optimal interactions between the GQD structural defects and the palladium nanoparticles was recorded. He et al. [69] prepared nanosized GQDs through acid etching of carbon fibers and used these as effective substratesupports for platinum nanoparticles $(\mathrm{Pt} / \mathrm{G})$, synthesized by thermolytic reduction of platinum (II) chlo- 
ride in ethylene glycol. The as-synthesized $\mathrm{Pt} / \mathrm{G}$ particles showed enhanced catalytic activity during reduction of oxygen, with an onset potential of $+1.05 \mathrm{~V}$. This result was $70 \mathrm{mV}$ more positive than that of $\mathrm{Pt} / \mathrm{C}$, and a specific activity almost nine times higher, showing better activity of $\mathrm{Pt} / \mathrm{G}$ over commercial $\mathrm{Pt} / \mathrm{C}$ catalysts. These results were ascribed to the abundant structural defects of the nanosized GQDs that manipulated the dissociative adsorption of oxygen and the binding of reaction intermediates $\mathrm{O}^{*}$ and $\mathrm{HO}^{*}$ on platinum surfaces. Another GQD supported platinum nanocatalyst $(\mathrm{Pt} / \mathrm{G})$ was prepared by Song et al. [30] for ORR. The electrocatalytic performance was accounted by the deliberate manipulation of the adsorption of oxygen and reaction intermediates on platinum by the GQD structural defects through partial charge transfer. Pt-GQD catalysts were prepared at different conditions, however, materials at two reaction conditions $\left(160^{\circ} \mathrm{C}\right.$ for $12 \mathrm{~h}$ and $180^{\circ} \mathrm{C}$ for $6 \mathrm{~h}$ ) exhibited maximum efficiencies (kinetic current densities of 29.2 and $24.6 \mathrm{~A} / \mathrm{m}^{2}$ at $+0.90 \mathrm{~V}$, respectively). Apart from platinum noble metal, gold has also been used for catalysis due to its lower cost and effective catalytic activity. The activity of gold nanoparticles with GQD support has been explored by Luo et al. [70]. They prepared GQD/gold nanoparticle hybrid (Au@GQDs core-shell nanostructure with an average diameter of $15.6 \mathrm{~nm}$ ) and used it for catalytic HER in $0.5 \mathrm{M} \mathrm{H}_{2} \mathrm{SO}_{4}$ medium. The Tafel slopes were 78 and $75 \mathrm{mV} / \mathrm{dec}$, respectively for Au@GQD and Au nanoparticles, but the former had a lower over potential compared to latter. The higher activity of the composite was attributed to the strong chemical coupling/interactions between components GQD and Au nanoparticles. The strong GQDs coating layer at Au surface prevented the aggregation of $\mathrm{Au}$ nanoparticles and boosted the activity. Liu et al. synthesized a $\mathrm{Cu}_{2} \mathrm{O} / \mathrm{CuO}-\mathrm{GQD}$ composite for alkaline electroreduction of oxygen [71]. The $\mathrm{Cu} / \mathrm{C}$ ratio played an important role during catalysis. The comparison of the activity of $\mathrm{Cu} / \mathrm{GQD}$ nanocomposite with $\mathrm{Pt} / \mathrm{GQD}$ and $\mathrm{Pt} / \mathrm{C}$ showed that the composite had the lowest onset potential towards ORR. Non-noble metal based GQD catalysts also showed enhanced catalytic activity. Koh et al. conjugated iron (II) phthalocyanine (FePC) with GQDs and used the catalyst for ORR in alkaline medium [72]. The catalyst also showed potential tolerance against methanol and carbon dioxide. The FePC-
GQD catalyst followed a four-electron path and reduced oxygen directly to $\mathrm{OH}^{-}$in alkaline electrolyte, with the Tafel slope of the reaction being $23 \mathrm{mV}$ $\mathrm{dec}^{-1}$. When GQD followed a two-electron transfer process yielding $\mathrm{HO}_{2}^{-}$, the Tafel slope was $28.9 \mathrm{mVdec}^{-1}$, indicating the four-electron mechanism to be the preferable path. A GQD loaded and molybdenum doped porous $\mathrm{Ni}_{3} \mathrm{~S}_{2}$ hybrid $\left(\mathrm{G}-\mathrm{Mo}-\mathrm{Ni}_{3} \mathrm{~S}_{2}\right)$ was in situ grown on Ni foam by GQDs and was used for overall water splitting by Li et al. [73]. The in situ coupling of GQD with metal hybrid modified the electronic behavior of the catalyst and exposed more active sites for reaction. This boosted the overpotential of HER and OER by $68 \mathrm{mV}$ at $10 \mathrm{~mA} \mathrm{~cm}^{-2}$ and $326 \mathrm{mV}$ at $20 \mathrm{~mA} \mathrm{~cm}^{-2}$ in $1.0 \mathrm{M} \mathrm{KOH}$, respectively. The twoelectrode cell, using G-Mo- $\mathrm{Ni}_{3} \mathrm{~S}_{2}$, was constructed to deliver low cell voltage of $1.58 \mathrm{~V}$ at water-splitting current of $10 \mathrm{~mA} \mathrm{~cm}^{-2}$ with a significant stability for more than $50 \mathrm{~h}$. Chen et al. used GQDs to enhance the activity of $\mathrm{Bi}_{2} \mathrm{O}_{3}$ nanosheet for reduction of $\mathrm{CO}_{2}$ to formate [74]. The as prepared $\mathrm{Bi}_{2} \mathrm{O}_{3}$-NGQDs demonstrated a nearly $100 \%$ formate Faraday Efficiency (FE) at a moderate overpotential of $0.7 \mathrm{~V}$ with a good stability and a high activity. The DFT calculation suggested that the increase in activity could be attributed to better adsorption of reaction intermediate at the GQD surface. In Figure 7, the experimental results and schematics of synthesis are documented.

Vinoth et al. [75] decorated N-doped GQDs (N$\mathrm{GQDs})$ on a $3 \mathrm{D} \mathrm{MoS}_{2}$-reduced graphene oxide ( $\mathrm{rGO}$ ) framework via a facile hydrothermal method for ORR. They concluded that the chemical interaction between the electroactive N-GQDs and $\mathrm{MoS}_{2}-\mathrm{rGO}$ increased surface area and pore size of the N-GQDs/ $\mathrm{MoS}_{2}$-rGO nanohybrid synergistically, which in turn improved the ORR onset potential to $+0.81 \mathrm{~V}$ vs reversible hydrogen electrode (RHE). Moreover, the $\mathrm{N}-\mathrm{GQDs} / \mathrm{MoS}_{2}$-rGO nanohybrid showed better ORR stability for up to 3000 cycles with negligible deviation in the half-wave potential. Lv et al. [76] fabricated a noble metal-free electrocatalyst via in situ formation of nanocomposite of N-doped GQDs (NGQDs) and $\mathrm{Ni}_{3} \mathrm{~S}_{2}$ nanosheets on the $\mathrm{Ni}$ foam $\left(\mathrm{Ni}_{3} \mathrm{~S}_{2}\right.$-NGQDs/NF). The resultant $\mathrm{Ni}_{3} \mathrm{~S}_{2}$-NGQDs/ NF served as an active, binder-free, and self-supported catalytic electrode for direct water splitting. At a current density of $10 \mathrm{~mA} \mathrm{~cm}{ }^{-2}$, the overpotential was $216 \mathrm{mV}$ for OER and $218 \mathrm{mV}$ for HER in alkaline media. This bifunctional electrocatalyst enabled 

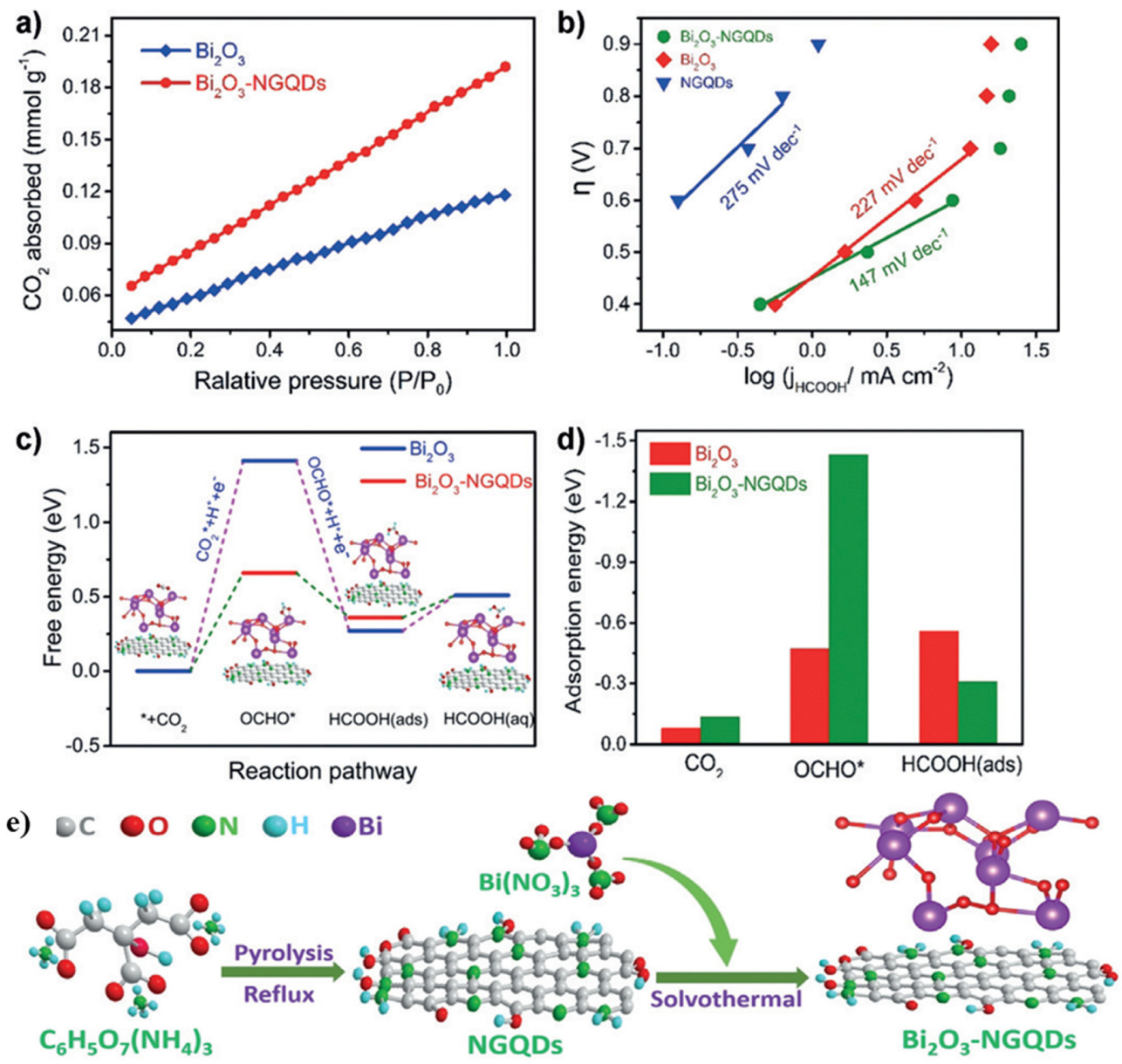

Fig. 7. a) $\mathrm{CO}_{2}$ adsorption isotherm for $\mathrm{Bi}_{2} \mathrm{O}_{3}$ and $\mathrm{Bi}_{2} \mathrm{O}_{3}-\mathrm{NGQDs}$. b) Tafel plots for the $\mathrm{Bi}_{2} \mathrm{O}_{3}-\mathrm{NGQDs}, \mathrm{Bi}_{2} \mathrm{O}_{3}$, and NGQDs. DFT calculations for the electrochemical reduction of $\mathrm{CO}_{2}$ to formate process over $\mathrm{Bi}_{2} \mathrm{O}_{3}-\mathrm{NGQDs}$ and $\mathrm{Bi}_{2} \mathrm{O}_{3}$. c) Calculated free-energy diagram. d) Calculated adsorption energy of $\mathrm{CO}_{2}, \mathrm{OCHO}^{*}$, and $\mathrm{HCOOH}$ (ads). e) Schematic of the synthesis process for $\mathrm{Bi}_{2} \mathrm{O}_{3}$-NGQDs. Reprinted with permission from Reference [74]. Copyright (C) 2018 Wiley-VCH Verlag GmbH \& Co. KGaA, Weinheim.

the construction of an alkali electrolyzer with a low cell voltage of $1.58 \mathrm{~V}$ vs. reversible hydrogen electrode (RHE) at $10 \mathrm{~mA} \mathrm{~cm}^{-2}$.

Apart from GQD metal/metal oxide composites, metal free GQD/carbon nanoparticle composites were also investigated for different electrocatalytic reactions. Luo et al. synthesized a GQD supported $\mathrm{N}, \mathrm{S}$-co doped reduced graphene oxide $(\mathrm{N}, \mathrm{S}-\mathrm{RGO} /$ GQDs) by microwave treatment for ORR in alkaline medium [77]. The doping enhanced the catalytic activity. The onset potential, reduction peak, and the limiting current of N,S-RGO/GQDs hybrids potential of were $-0.10 \mathrm{~V}$ and $-0.25 \mathrm{~V}$, and $4.53 \mathrm{~mA} \mathrm{~cm}^{-2}$ (at -
$0.8 \mathrm{~V}$ a rotary speed of $1600 \mathrm{rpm}$ ), respectively. These results showed that $\mathrm{N}, \mathrm{S}-\mathrm{RGO} / \mathrm{GQD}$ s have good catalytic activity and are potential metal- free catalyst for the ORR in an alkaline solution through a four electron mechanism. Yao et al. prepared Sdoped GQD decorated carbon nanoparticles (SGQDs/CNPs) from dehydration of fructose and $\mathrm{H}_{2} \mathrm{SO}_{4}$ for ORR [78]. The low reduction peak at $0.396 \mathrm{~V}$ and high peak current density of $-2.02 \mathrm{~mA} /$ $\mathrm{cm}^{2}$ showed the efficiency of the composite. From the experimental data, the layer by layer modified method could inhibit the occurrence of a two-electron pathway and cause a four-electron pathway for ORR. 
The S-GQDs/CNP nanohybrid showed better methanol tolerance and long-term durability than commercial 20\% Pt/C. Wang et al. [79] reported synergistic within GQD and graphene hydrogen composite during electroreduction of oxygen. The nanocomposite exhibited fine ORR activity and durability in alkaline solution, which showed a comparable discharge performance of zinc/air batteries with $\mathrm{Pt} / \mathrm{C}$ under a current density of $20 \mathrm{~mA} \mathrm{~cm}{ }^{-2}$. The high performance was attributed to the rich edge defects present at the composite surface. Graphene nano ribbons (GNR) were also reported to get support from GQD and perform as excellent electrocatalyst for oxygen reduction. Jin et al. [80] prepared a GQD/GNR composite for ORR in $0.1 \mathrm{M} \mathrm{KOH}$ medium, with the numerous surface/edge defects on the GQD/GNR surfaces and at their interface acting as the active sites. This, coupled with efficient charge transfer between the intimately contacted GQDs and GNRs, rationalized the observed electrocatalytic performance. The Tafel slope was measured to be $\sim 87.7$ $\mathrm{mV}$ per decade, indicating high efficiency. The catalyst showed significant stability over $26 \mathrm{hrs}$. Hasanzadeh et al. prepared a GQD functionalized by chitosan (CS) and beta-cyclodextrin ( $\beta$-CD) as a new support nanocomposite material for efficient methanol electrooxidation [81]. The anodic peak currents showed a linear relationship with the square root of the scan rate for characteristic diffusion-controlled process. The overall electron transfer coefficients were 0.44 and 0.5 while the Tafel slopes were $0.7 \mathrm{mV}$ and $0.63 \mathrm{~V}$ for $\mathrm{CS}$ and $\beta$-CD support, respectively towards methanol oxidation. The observed peak current values indicated the essential roles of CS and $\beta$ -
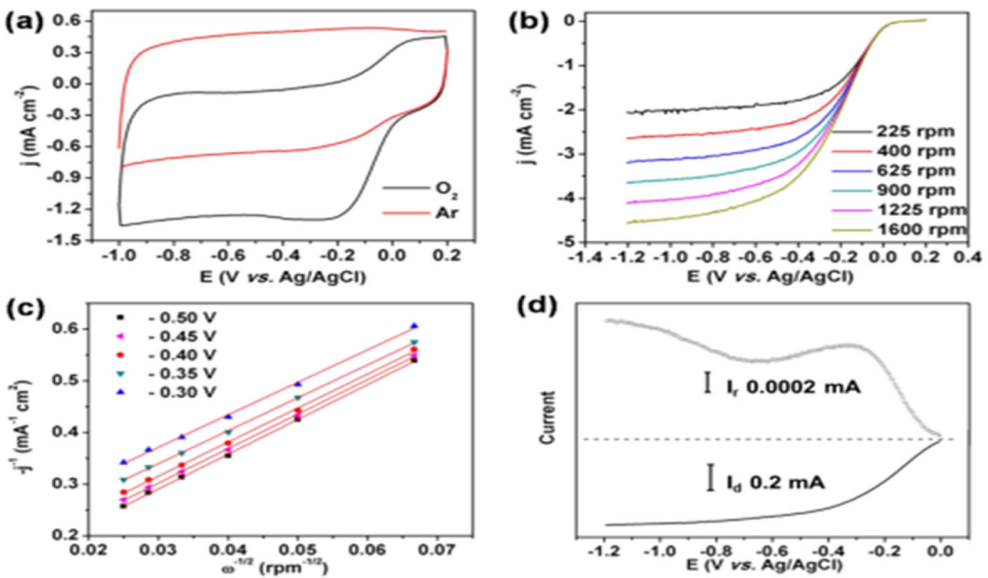

(e)

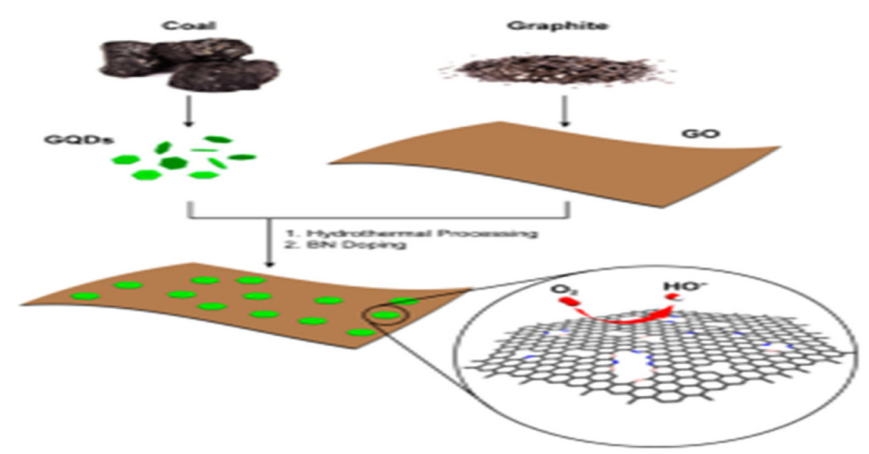

Fig. 8. (a) Cyclic voltammograms of ORR on $\mathrm{BN}-\mathrm{GQD} / \mathrm{G}-30$ in $\mathrm{Ar}$ - and $\mathrm{O}_{2}$-saturated $0.1 \mathrm{M} \mathrm{KOH}$ solution at a scan rate of $100 \mathrm{mV} \mathrm{s}^{-1}$. (b) RDE linear sweep voltammograms of ORR on a BN-GQD/G-30 electrode at different rotating speeds in $\mathrm{O}_{2}$-saturated $0.1 \mathrm{M} \mathrm{KOH}$ solution with a scan rate of $5 \mathrm{mV} \mathrm{s}^{-1}$. (c) Koutecky-Levich plots of BN-GQD/G-30 derived from RDE voltammograms (b) at different potentials. (d) Rotating ring disk electrode voltammograms of ORR on a BN-GQD/G30 electrode with a scan rate of $5 \mathrm{mV} \mathrm{s}^{-1}$. (e) Illustration of the preparation procedure for the $\mathrm{BN}-\mathrm{GQD} / \mathrm{G}$ nanocomposite. Reprinted with permission from Reference [83]. Copyright (C) 2014 American Chemical Society. 
CD in the observed electrocatalytic behavior. Zhou et al. prepared another metal free electrocatalyst for reduction of oxygen [82]. The synergistic effect of GQD and multi walled carbon nanotube (MWCNT) was used for the catalysis in $\mathrm{O}_{2}$-saturated $0.1 \mathrm{M} \mathrm{KOH}$ solution. The GQD intake was optimized by considering the ratio of lattice and adsorbed oxygen in the composite. At optimized ratio of GQD-MWCNT, the ORR peak was observed at $-0.25 \mathrm{~V}$. The highest current density was obtained as $3.47 \mathrm{~mA} \mathrm{~cm}^{-2}$. Fei et al. synthesized a B,Ndoped GQDS/Graphene hybrid nanoplatelets for electrocatalysis of oxygen [83]. The electrochemical studies and the synthetic protocol are shown in Fig. 8.

The GQD particles self-assembled on graphene and the hybrid material combined the advantages of both components, such as abundant edges and doping sites, high electrical conductivity, and high surface area, making the resulting materials excellent oxygen reduction electrocatalyst with activity even higher than that of commercial $\mathrm{Pt} / \mathrm{C}$ in alkaline media. The optimum activity of the catalyst was obtained by tuning the concentration of doped atoms. The onset potential of composite at optimized condition, measured from the rotating disk electrode was $\sim 15 \mathrm{mV}$ more positive than of $\mathrm{Pt} / \mathrm{C}$. In addition, the diffusion-limited current density and current density of the composite was larger than that of $\mathrm{Pt} / \mathrm{C}$ within the range of 0.20 to $-0.15 \mathrm{~V}$ at the same mass loading, suggesting the higher ORR activity of the composite than $\mathrm{Pt} / \mathrm{C}$. For the four-electron transfer mechanism, the kinetic current density was obtained as $11.1 \mathrm{~mA}$ $\mathrm{cm}^{-2}$ for the composite.

\section{Conclusion and Perspective}

Intense effort has been put on to find suitable and efficient catalysts for different electrochemical reactions such as HER, OER, ORR for generation of clean and sustainable energy. As the alternative to expensive platinum, ruthenium and iridium-based catalysts CD particle with or without metal hybrid/ composite have emerged. The large surface area, facile electron transfer and tunable morphology of CD particles enables high catalytic action. The unique optoelectronic properties of CD particles can be tuned through their size, doping and surface functional groups. Doping of hetero atoms at the carbon core plays an important role in catalysis. The co-doping and concentration of dopant are also important.
The CD supported metallic or nonmetallic nanoparticles benefit from the unique properties of CD support. Furthermore, CD support might protect from catalyst poisoning and oxidation in reaction medium. Since the activity of $\mathrm{Pt} / \mathrm{C}$ catalyst depends on the $\mathrm{Pt}$ loading, the comparison between $\mathrm{Pt} / \mathrm{C}$ and $\mathrm{CD}$ based catalysts might vary at different conditions. $\mathrm{CD}$ based catalysts are yet to overcome the mass production related limitation to achieve ultimate activity to solve the energy issues. More strategist way for carbon supported nanoparticle synthesis have to be adopted to reduce side products and achieve maximum product. Synthesis of CD particles at an industrial scale is needed to widen their applications. Stability, resistance towards corrosion of electrodes and catalyst poisoning are also persisting problems for the electrocatalytic reactions that need tactical solutions.

In future, these limitations are expected to be overcome with more innovative and facile synthetic routes and precursors. More metal free catalysts would be explored to avoid metal related toxicity and corrosion. Doping of heteroatom such as sulphur, phosphorous etc. might be explored to achieve different synergistic interactions. Organic polymer dots might be applied as electrode material along with metal or nonmetal support. These different strategies towards employing a series of 0-D CD particles might enlighten future research. The potential use of CDs might be extended by combining their optical and electrochemical properties to fabricate low-cost commercial fluorescent electrodes.

\section{Acknowledgement}

This study was supported by the Basic Science Research Program through the National Research Foundation of Korea (NRF) funded by The Ministry of Science, ICT and Future Planning (NRF2019R1A2B5B02069683).

\section{References}

[1] M. Zhou, H. L. Wang, S. Guo, Chem. Soc. Rev., 2016, 45(5), 1273-1307.

[2] Y. Holade, K. Servat, S. Tingry, T. W. Napporn, H. Remita, D. Cornu, K. B. Kokoh, ChemPhysChem, 2017, 18919), 2573-2605.

[3] S. Y. Lim, W. Shen, Z. Gao, Chem. Soc. Rev., 2015, 44(1), 362-381.

[4] X. Xu, R. Ray, Y. Gu, H. J. Ploehn, L. Gearheart, K. 
Raker, W. A. Scrivens, J. Am. Chem. Soc., 2004, 126(40), 12736-12737.

[5] Y. P. Sun, B. Zhou, Y. Lin, W. Wang, K. A. S. Fernando, P. Pathak, M. J. Meziani, B. A. Harruff, X. Wang, H. Wang, P. G. Luo, H. Yang, M. E. Kose, B. Chen, L. M. Veca, S. Y. Xie, J. Am. Chem. Soc., 2006, 128(24), 7756-7757.

[6] H. Ding, S. B. Yu, J. S. Wei, H. M. Xiong, ACS Nano, 2016, 10(1), 484-491.

[7] S. N. Baker, G. A. Baker, Angew. Chemie - Int. Ed., 2010, 49(38), 6726-6744.

[8] H. Li, Z. Kang, Y. Liu, S. T. Lee, J. Mater. Chem., 2012, 22(46), 24230-24253.

[9] V. Vij, S. Sultan, A. M. Harzandi, A. Meena, J. N. Tiwari, W. G. Lee, T. Yoon, K. S. Kim, ACS Catal., 2017, 7(10), 7196-7225.

[10] J. Wang, F. Xu, H. Jin, Y. Chen, Y. Wang, Adv. Mater., 2017, 29(14), 1605838.

[11] N. Dubouis, A. Grimaud, Chem. Sci., 2019, 10(40), 9165-9181.

[12] V. C. Hoang, K. Dave, V. G. Gomes, Nano Energy, 2019, 66, 104093.

[13] G. Wu, N. Li, C. S. Dai, D. R. Zhou, Mater Chem. Phys., 2004, 83(2-3), 307-314.

[14] B. Y. W. Li, Y. Liu, M. Wu, X. Feng, S. A. T. Redfern, Y. Shang, X. Yong, T. Feng, K. Wu, Z. Liu, B. Li, Z. Chen, J. S. Tse, S. Lu, Adv. Mater., 2018, 30(31), 1800676.

[15] D. V. Esposito, S. T. Hunt, Y. C. Kimmel, J. G. Chen, J. Am. Chem.Soc., 2012, 134(6), 3025-3033.

[16] Y. Yang, J. Liu, S. Guo, Y. Liu, Z. Kang, J. Mater. Chem. A, 2015, 3(36), 18598-18604.

[17] J. Zheng, Electrochim. Acta, 2017, 247, 381-391.

[18] Y. Xu, M. Kraft, R. Xu, Chem. Soc. Rev., 2016, 45(11), 3039-3052.

[19] C. Hu, L. Dai, Angew. Chemie - Int. Ed., 2016, 55(39), $11736-11758$

[20] M. W. Chung, C. H. Choi, S. Y. Lee, S. I. Woo, Nano Energy, 2015, 11, 526-532.

[21] S. Zhu, Y. Song, X. Zhao, J. Shao, J. Zhang, B. Yang, Nano Res., 2015, 8(2), 355-381.

[22] M. Semeniuk, Z. Yi, V. Poursorkhabi, J. Tjong, S. Jaffer, Z. H. Lu and M. Sain, ACS Nano, 2019, 13(6), 62246255.

[23] K. S. Novoselov, A. K. Geim, S. V Morozov, D. Jiang, Y. Zhang, S. V Dubonos, I. V Grigorieva, A. A. Firsov, Science, 2004, 306(5696), 666-669.

[24] S. Tang, W. Wu, X. Xie, X. Li, J. Gu, RSC Adv., 2017, 7(16), 9862-9871.

[25] C. Hu, Y. Xiao, Y. Zou, L. Dai, Electrochem. Energy Rev., 2018, 1(1), 84-112.

[26] J. Zhang, Z. Xia, L. Dai, Sci. Adv., 2015, 1(7), e1500564.

[27] P. Zhang, J. S. Wei, X. B. Chen, H. M. Xiong, J. Colloid Interface Sci., 2019, 537, 716-724.

[28] Z. Lei, S. Xu, J. Wan, P. Wu, Nanoscale, 2016, 8(4),
2219-2226.

[29] D. W. Zheng, B. Li, C. X. Li, J. X. Fan, Q. Lei, C. Li, Z. Xu,X. Z. Zhang, ACS Nano, 2016, 10(9), 8715-8722.

[30] Y. Song, S. Chen, ACS Appl. Mater. Interfaces, 2014, 6(16), 14050-14060.

[31] W. Li, Z. Wei, B. Wang, Y. Liu, H. Song, Z. Tang, B. Yang, S. Lu, Mater. Chem. Front., 2020, 4(1), 277-284.

[32] L. SGao, Y Chen, HFan, X Wei, C Hu, Li Wang, $J$. Mater. Chem. A, 2014, 2(18), 6320-6325.

[33] K. Kakaei, H. Javan, M. Khamforoush, S. A. Zarei, Int. J. Hydrogen Energy, 2016, 41(33), 14684-14691.

[34] S. Bhattacharyya, B. Konkena, K. Jayaramulu, W. Schuhmann, T. K. Maji, J. Mater. Chem. A, 2017, 5(26), 13573-13580.

[35] R. Atchudan, T. N. J. I. Edison, Y. R. Lee, J. Colloid Interface Sci., 2016, 482, 8-18.

[36] E. Martínez-Periñán, I. Bravo, S. J. Rowley-Neale, E. Lorenzo, C. E. Banks, Electroanalysis, 2018, 30(3), 436444.

[37] A. Datta, S. Kapri, S. Bhattacharyya, J. Mater. Chem. A, 2016, 4(38), 14614-14624.

[38] J. Shen, Y. Li, Y. Su, Y. Zhu, H. Jiang, X. Yang, C. Li, Nanoscale, 2015, 7(5), 2003-2008.

[39] K. Kakaei, Int. J. Hydrogen Energy, 2017, 42(16), 11605-11613.

[40] T. Bao, L. Song, S. Zhang, Chem. Eng. J., 2018, 351, 189-194.

[41] W. Li, Y. Liu, M. Wu, X. Feng, S. A. T. Redfern, Y. Shang, X. Yong, T. Feng, K. Wu, Z. Liu, B. Li, Z. Chen, J. S. Tse, S. Lu, B. Yang, Adv. Mater., 2018, 30(31), $1800676(1-8)$.

[42] Q. Dang, F. Liao, Y. Sun, S. Zhang, H. Huang, W. Shen, Z. Kang, Y. Shi, M. Shao, Electrochim. Acta, 2019, 299, 828-834.

[43] Y. Liu, X. Li, Q. Zhang, W. Li, Y. Xie, H. Liu, L. Shang, Z. Liu, Z. Chen, L. Gu, Z. Tang, T. Zhang, S. Lu, Angew. Chemie - Int. Ed., 2020, 59(4), 1718-1726.

[44] G. Li, S. Hou, L. Gui, F. Feng, D. Zhang, B. He, L. Zhao, Appl. Catal. B Environ., 2019, 257, 117919.

[45] L. Tian, J. Wang, K. Wang, H. Wo, X. Wang, W. Zhuang, T. Li, X. Du, Carbon, 2019, 143, 457-466.

[46] P. Zhang, D. Bin, J. S. Wei, X. Q. Niu, X. B. Chen, Y. Y. Xia, H. M. Xiong, ACS Appl. Mater. Interfaces, 2019, 11(15), 14085-14094.

[47] S. Zhao, C. Li, J. Liu, N. Liu, S. Qiao, Y. Han, H. Huang, Y. Liu, Z. Kang, Carbon, 2015, 92, 64-73.

[48] D. Tang, J. Liu, X. Wu, R. Liu, X. Han, Y. Han, H. Huang, Y. Liu, Z. Kang, ACS Appl. Mater. Interfaces, 2014, 6(10), 7918-7925.

[49] R. Canton-Vitoria, L. Vallan, E. Urriolabeitia, A. M. Benito, W. K. Maser, N. Tagmatarchis, Chem. - A Eur. J., 2018, 24(41), 10468-10474.

[50] Z. Y. Shih, A. P. Periasamy, P. C. Hsu, H. T. Chang, Appl. Catal. B Environ., 2013, 132-133, 363-369.

[51] L. Wang, S. Zhao, X. Wu, S. Guo, J. Liu, N. Liu, H. Huang, Y. Liu, Z. Kang, RSC Adv., 2016, 6(71), 66893- 
66899.

[52] L. Zhang, Y. Yang, M. A. Ziaee, K. Lu, R. Wang, ACS Appl. Mater. Interfaces, 2018, 10(11), 9460-9467.

[53] S. Zhao, C. Li, H. Huang, Y. Liu, Z. Kang, J. Mater., 2015, 1(3), 236-244.

[54] J. Cao, Y. Hu, L. Chen, J. Xu, Z. Chen, Int. J. Hydrogen Energy, 2017, 42(5), 2931-2942.

[55] S. Guo, S. Zhao, X. Wu, H. Li, Y. Zhou, C. Zhu, N. Yang, X. Jiang, J. Gao, L. Bai, Y. Liu, Y. Lifshitz, S. T. Lee, Z. Kang, Nat. Commun., 2017, 8(1), 1-9.

[56] J. Zhang, J. Chen, Y. Luo, Y. Chen, X. Wei, G. Wang, R. Wang, Appl. Surf. Sci., 2019, 466, 911-919.

[57] C. Hu, C. Yu, M. Li, X. Wang, Q. Dong, G. Wang, J. Qiu, Chem. Commun., 2015, 51(16), 3419-3422.

[58] M. Wang, J. Fang, L. Hu, Y. Lai, Z. Liu, Int. J. Hydrogen Energy, 2017, 42(33), 21305-21310.

[59] L. Zhou, P. Fu, Y. Wang, L. Sun, Y. Yuan, J. Mater. Chem. A, 2016, 4(19), 7222-7229.

[60] W. J. Niu, R. H. Zhu, Yan-Hua, H. B. Zeng, S. Cosnier, X. J. Zhang, D. Shan, Carbon, 2016, 109, 402-410.

[61] H. Zhang, Y. Wang, D. Wang, Y. Li, X. Liu, P. Liu, H. Yang, T. An, Z. Tang, H. Zhao, Small, 2014, 10(16), 3371-3378.

[62] H. Liu, Q. Zhao, J. Liu, X. Ma, Y. Rao, X. Shao, Z. Li, W. Wu, H. Ning, M. Wu, Appl. Surf. Sci., 2017, 423, 909-916.

[63] L. L. Qiqi Li, Sheng Zhang, Liming Dai, J. Am. Chem. Soc., 2012, 134(46), 18932-18935.

[64] R. Yan, H. Wu, Q. Zheng, J. Wang, J. Huang, K. Ding, Q. Guo, J. Wang, RSC Adv., 2014, 4, 23097-23106.

[65] J. P. Guin, S. K. Guin, T. Debnath, H. N. Ghosh, Carbon, 2016, 109, 517-528.

[66] M. Favaro, L. Ferrighi, G. Fazio, L. Colazzo, C. Di Valentin, C. Durante, F. Sedona, A. Gennaro, S. Agnoli, G. Granozzi, ACS Catal., 2015, 5(1), 129-144.

[67] C. P. Deming, R. Mercado, J. E. Lu, V. Gadiraju, M. Khan, S. Chen, ACS Sustain. Chem. Eng., 2016, 4(12), 6580-6589.
[68] C. P. Deming, R. Mercado, V. Gadiraju, S. W. Sweeney, M. Khan, S. Chen, ACS Sustain. Chem. Eng., 2015, 3(12), 3315-3323.

[69] G. He, Y. Song, K. Liu, A. Walter, S. Chen, S. Chen, ACS Catal., 2013, 3(5), 831-838.

[70] P. Luo, L. Jiang, W. Zhang, X. Guan, Chem. Phys. Lett., 2015, 641, 29-32.

[71] K. Liu, Y. Song, S. Chen, Int. J. Hydrogen Energy, 2016, 41(3), 1559-1567.

[72] K. H. Koh, S. H. Noh, T. H. Kim, W. J. Lee, S. C. Yi, T. H. Han, RSC Adv., 2017, 7(42), 26113-26119.

[73] J. Li, X. Zhang, Z. Zhang, Z. Li, M. Gao, H. Wei, H. Chu, Electrochim. Acta, 2019, 304, 487-494.

[74] Z. Chen, K. Mou, X. Wang, L. Liu, Angew. Chemie, 2018, 130(39), 12972-C12976

[75] R. Vinoth, I. M. Patil, A. Pandikumar, B. A. Kakade, N. M. Huang, D. D. Dionysios, B. Neppolian, ACS Omega, 2016, 1(5), 971-980.

[76] J. J. Lv, J. Zhao, H. Fang, L. P. Jiang, L. L. Li, J. Ma, J. J. Zhu, Small, 2017, 13, 1-10.

[77] Z. Luo, D. Yang, G. Qi, J. Shang, H. Yang, Y. Wang, L. Yuwen, T. Yu, W. Huang, L. Wang, J. Mater. Chem. A, 2014, 2(48), 20605-20611.

[78] Y. Yao, Y. Guo, W. Du, X. Tong, X. Zhang, J. Mater. Sci. Mater. Electron., 2018, 29(20), 17695-17705.

[79] M. Wang, Z. Fang, K. Zhang, J. Fang, F. Qin, Z. Zhang, J. Li, Y. Liu, Y. Lai, Nanoscale, 2016, 8(22), 1139811402.

[80] H. Jin, H. Huang, Y. He, X. Feng, S. Wang, L. Dai, J. Wang, J. Am. Chem. Soc., 2015, 137(24), 7588-7591.

[81] M. Hasanzadeh, N. Shadjou,M. Marandi, J. Alloys Compd., 2016, 688, 171-186.

[82] X. Zhou, Z. Tian, J. Li, H. Ruan, Y. Ma, Z. Yang, Y. Qu, Nanoscale, 2014, 6(5), 2603-2607.

[83] H. Fei, R. Ye, G. Ye, Y. Gong, Z. Peng, X. Fan, E. L. G. Samuel, P.M. Ajayan, J. K. Tour, ACS Nano, 2014, 8(10), 10837-10843 